April 1999 • NREL/SR-570-26158

\title{
Recycling and Energy Recovery Pilot Project: Project Report And Future Efforts
}

C. Rivard

Pinnacle Biotechnologies International, Inc. Golden, Colorado

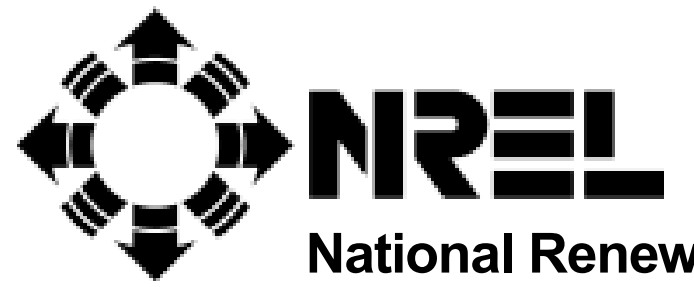

1617 Cole Boulevard

Golden, Colorado 80401-3393

NREL is a U.S. Department of Energy Laboratory

Operated by Midwest Research Institute $\bullet$ Battelle $\bullet$ Bechtel

Contract No. DE-AC36-98-G010337 


April $1999 \quad \cdot$ NREL/SR-570-26158


Recycling and Energy Recovery
Pilot Project: Project Report
And Future Efforts

C. Rivard

Pinnacle Biotechnologies International, Inc. Golden, Colorado

NREL Technical Monitor: Carlton Wiles

Prepared under Subcontract No. TCG-6-16623

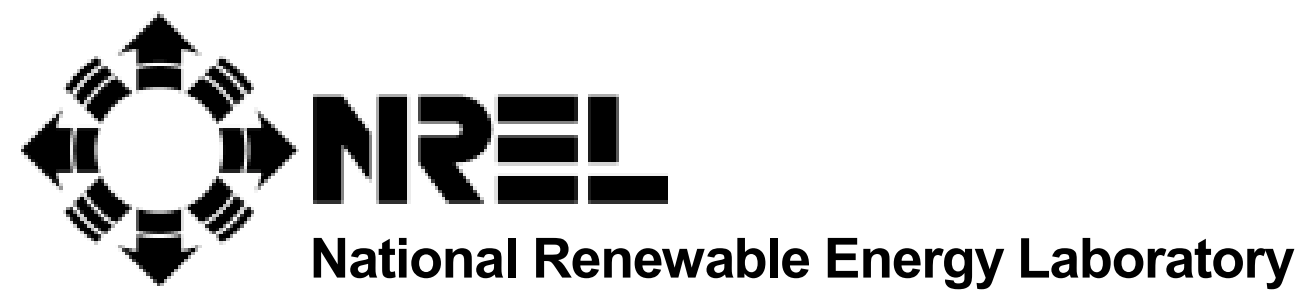

1617 Cole Boulevard

Golden, Colorado 80401-3393

NREL is a U.S. Department of Energy Laboratory

Operated by Midwest Research Institute $\bullet$ Battelle $\bullet$ Bechtel

Contract No. DE-AC36-98-G010337 


\section{NOTICE}

This report was prepared as an account of work sponsored by an agency of the United States government. Neither the United States government nor any agency thereof, nor any of their employees, makes any warranty, express or implied, or assumes any legal liability or responsibility for the accuracy, completeness, or usefulness of any information, apparatus, product, or process disclosed, or represents that its use would not infringe privately owned rights. Reference herein to any specific commercial product, process, or service by trade name, trademark, manufacturer, or otherwise does not necessarily constitute or imply its endorsement, recommendation, or favoring by the United States government or any agency thereof. The views and opinions of authors expressed herein do not necessarily state or reflect those of the United States government or any agency thereof.

Available to DOE and DOE contractors from:

Office of Scientific and Technical Information (OSTI)

P.O. Box 62

Oak Ridge, TN 37831

Prices available by calling 423-576-8401

Available to the public from:

National Technical Information Service (NTIS)

U.S. Department of Commerce

5285 Port Royal Road

Springfield, VA 22161

$703-605-6000$ or $800-553-6847$

or

DOE Information Bridge

http://www.doe.gov/bridge/home.html

Printed on paper containing at least $50 \%$ wastepaper, including $20 \%$ postconsumer waste 


\section{Recycling and Energy Recovery Pilot Project}

\section{Project Report and Future Efforts}

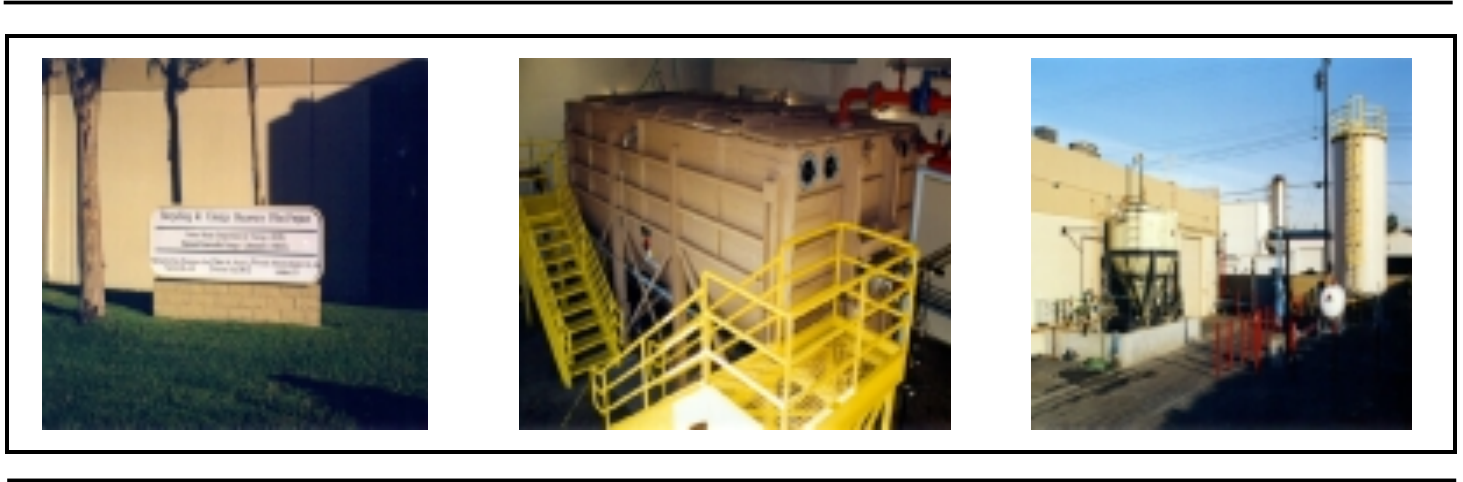

Report Prepared by

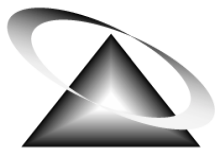

Pinnacle Biotechnologies International, Inc.

1667 Cole Blvd., Suite 400, Golden, CO 80401

\section{In Cooperation with}

Bioengineering Resources, Inc.

1650 Emmaus Road, Fayetteville, AR 72701

March 1999 


\section{Table of Contents}

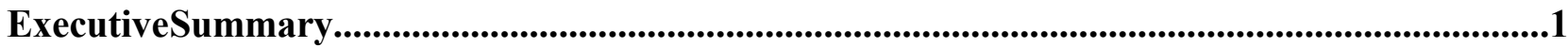

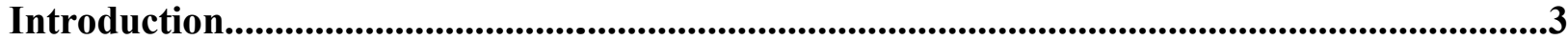

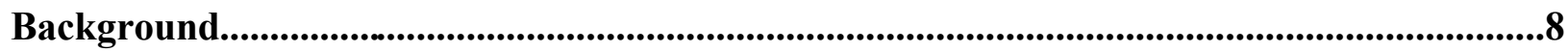

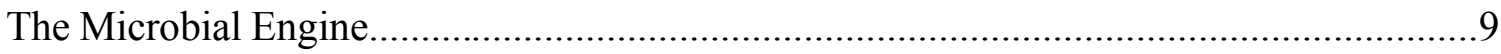

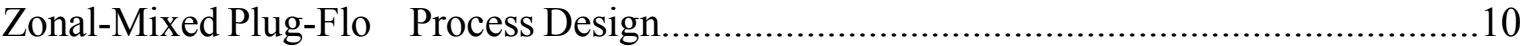

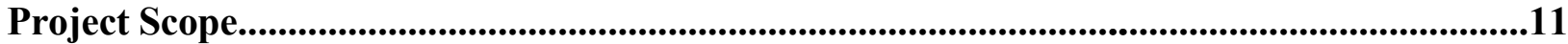

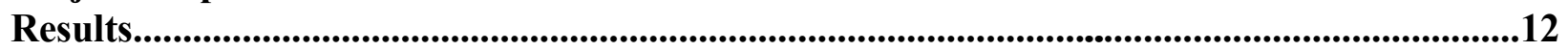

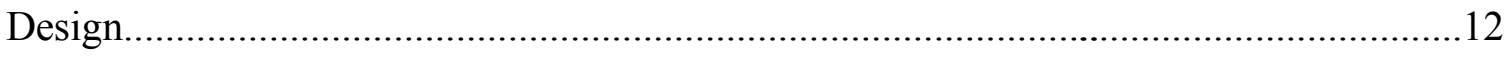

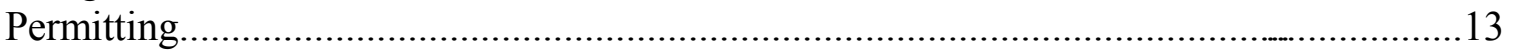

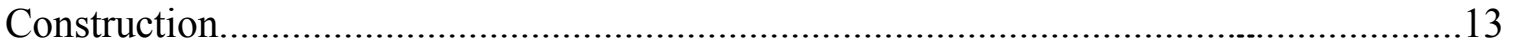

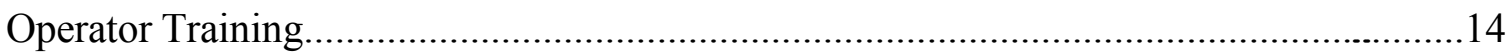

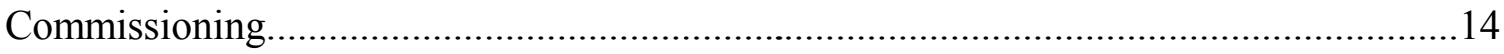

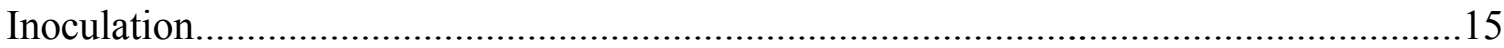

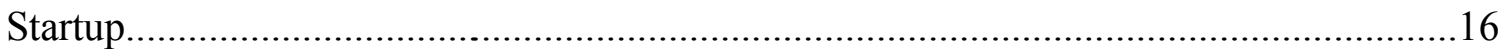

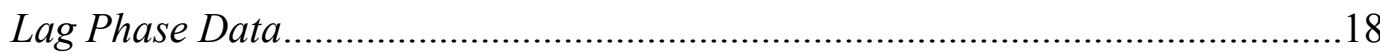

High Free Ammonia Levels...................................................................................19

pH Imbalance from Changing Food Waste Feedstock .......................................20

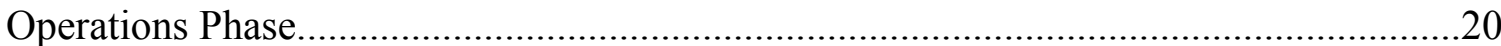

System Operating Restrictions..............................................................20

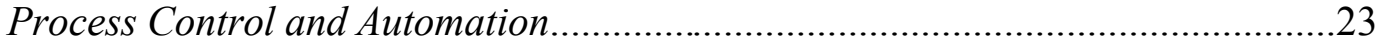

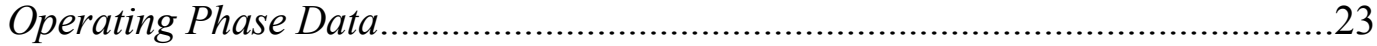

Mass Balance Calculations..............................................................................25

Energy Balance Calculations.......................................................................26

Conclusions........................................................................................................................................227

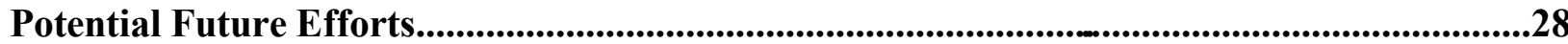

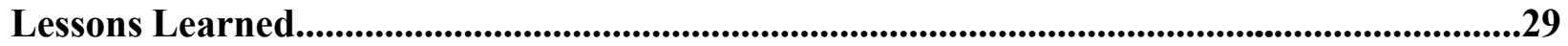

Specific Mechanical and Operational Issues....................................................................31

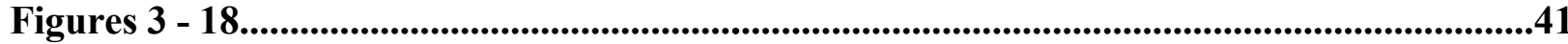

References..............................................................................................................................................57

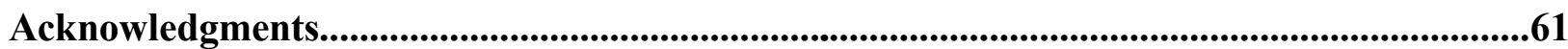




\section{Executive Summary}

A novel bioprocessing technology was developed that efficiently converts negative-value organic wastes, including domestic refuse, animal manures, industrial wastes, food processing wastes and municipal sewage sludge into saleable products, including fuel gas and compost. This technology is known as high solids anaerobic digestion (HSAD) and was developed at the National Renewable Energy Laboratory (NREL) from fundamental research to laboratory and intermediate-scale system evaluations. With funding from the U.S. Department of Energy, a pilot demonstration facility was constructed and operated in Orange County, California to validate the HSAD process rates and yields. The system was designed to process a maximum of 3 tons per day of mixed wastes. The project involved NREL, Bioengineering Resources, Inc., Black \& Veatch Engineering, Pinnacle Biotechnologies International, Inc., and US Filter/Envirex. The pilot system was designed to produce sufficient fuel gas to drive a 25-kilowatt cogeneration system. The process effluent represents a hygienic high-grade organic fertilizer for agricultural and nursery markets. The pilot system was designed for automated process control using Gensym G2/Factory Floor software. Manual operator involvement was limited to daily receipt of process waste feedstocks, compost product shipment, materials analysis, equipment maintenance, and process oversight.

The pilot plant has completed design, permitting, construction, commissioning, startup, and an initial operations period. Owing to the emerging nature of the technology and the fact that it was unknown to the host community, permitting requirements were extensive and delayed the start of plant construction. One of the unique features of the HSAD process is the thermophilic or hightemperature microbial consortium, which acts as the process catalyst. Due to the limited quantity of thermophilic starter culture, a larger volume of dewatered municipal anaerobic sludge or "filler sludge" was used to initiate the HSAD bioreactor. Early process imbalance caused by the large amount of filler sludge, together with several mechanical problems, conspired to slow the progression of the anaerobic culture toward critical mass. Following an extensive lag phase, the HSAD consortium reached critical mass and the system was determined to be ready for demonstration at increased organic loading rates. The HSAD process was verified at organic loading rates approaching 15 kilograms of volatile solids per cubic meter of sludge volume per day while achieving approximately $80 \%$ or better of the anticipated conversion to the fuel gas product (based on the VS loading). The average anaerobic yield was $0.279{ }^{3} \mathrm{CH}_{4} / \mathrm{kg}$ VS•d. Fuel gas methane content averaged 57.4\%. Although the vendor assured project personnel that the agitator system would meet performance specifications, it did not. This resulted in the mixing system not being able to mix at the higher solids levels originally planned by the project investigators. Therefore, this adversely affected testing at the higher organic loading rates. However, the HSAD system demonstrated remarkable resiliency to variations in organic loading and feedstock composition demonstrating good immediate (first $24 \mathrm{~h}$ ) conversion yields. The HSAD process mass balance closure was determined within $8 \%$ of the theoretical. Owing to the small capacity of the demonstration system, the calculated electrical energy parasitic load 
was substantial. Even under the most optimized operation, the calculated electrical parasitic load was approximately 43\%. It is anticipated that further economies of scale associated with larger, commercial-scale HSAD operations would allow parasitic loads of less than $15 \%$ to $20 \%$.

Pilot plant operations were curtailed in mid-May when the original project funding was exhausted. While the plant is currently maintained in stasis, it is available for demonstrations and tours. One of the project participants, Pinnacle Biotechnologies International, Inc., is actively soliciting for private funding for an additional 12- to 18-month operating phase to complete process validation at higher organic loading rates. The operating period would also be used to provide smaller scale testing of alternative organic waste feedstocks of interest to California, and prepare sufficient starter culture (effluent product) to rapidly initiate the first commercial HSAD system.

Even though the pilot plant effort did not completely meet the original project objectives relative to the target process organic loading rate, the project is viewed as a success for the following reasons:

- The plant was operated over an extended period of time using actual MSW and food processing wastes and effectively met all material handling challenges.

- The pilot plant was operated close to sensitive neighbors in a light industrial area with essentially no complaints regarding odor, noise, or vehicle traffic.

- Numerous important issues regarding plant equipment integration were identified and resolved, paving the way for a refined commercial system development.

- The plant computer automation and control software worked well and dramatically reduced the requirement for operator attention to the process.

- $\quad$ During the limited operating phase of the project, the HSAD biocatalyst performed very near to expectations relative to process rates and yields.

- The development and implementation of comprehensive operating and safety procedures resulted in a high level of operational safety and a low instance of unexpected complications.

- The HSAD system consistently produced high-quality fuel gas during the operating phase of the project.

The information gained during the design, permitting, construction, commissioning, startup, and operating phases of this pilot project will surely enhance the subsequent development of commercial scale HSAD plants by reducing the perceived risk associated with emerging technologies. HSAD process rates and economics closely approximated those determined in smaller-scale system testing, verifying the technology at near commercial scale. 


\section{Introduction}

The U.S. Department of Energy (DOE) with the U.S. Environmental Protection Agency (EPA), other territorial governments, and private industries have funded the development of a novel approach to anaerobic digestion for solid organic wastes. This technology is referred to as high solids anaerobic digestion (HSAD) or anaerobic composting and enables recycling of a wide variety of organic wastes to useful, value-added products, including fuel gas and compost. The HSAD process was developed through bench-, laboratory-, and intermediate-scale testing at the National Renewable Energy Laboratory (NREL). The development of the HSAD technology has been documented in numerous scientific publications (1-27) and government reports (28-37). The HSAD process employs a unique group of high-temperature (thermophilic) microorganisms that ferment the organics in waste to a medium Btu fuel gas and a safe organic compost and liquid fertilizer products. A generalized process description is presented in Figure 1.

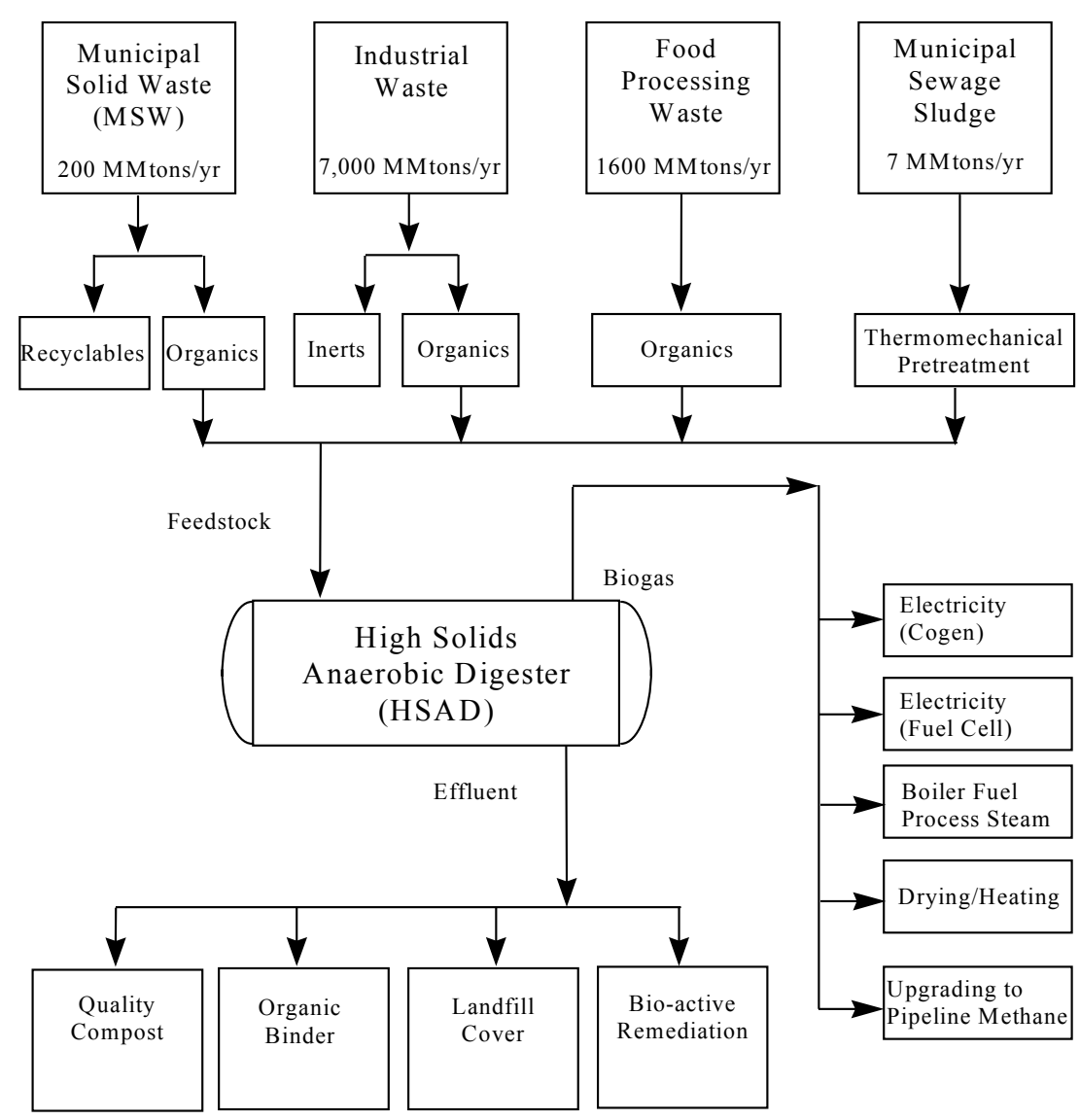

Figure 1. Generalized HSAD Process Flow Diagra 
The HSAD process represents a novel approach to the anaerobic bioconversion of organic wastes by achieving improvements in process rates, yields, and stability, and by reducing capital and operating costs. All this is accomplished by reducing the amount of process water. The HSAD process is amenable to the conversion of a wide variety of organic wastes including the organic fraction of municipal solid waste (MSW), agricultural residues, food processing wastes, organic industrial wastes, animal manures, and even sewage sludge (biosolids). The HSAD process is effective on solid and liquid wastes, although it is preferable to maintain a feed solids level of $25 \%$ to $60 \%$. Therefore, it is often desirable to blend liquid organic wastes with solid wastes such as MSW before use in the HSAD process. Blending organic wastes may also be beneficial where the composition of one waste is troublesome in treating it alone.

The HSAD process results in two value-added products, fuel gas and a compost product. The fuel gas product may be used in a large number of applications similar to natural gas. The Btu value of the fuel gas ranges from 500 to $650 \mathrm{Btu} / \mathrm{ft}^{3}$. The direct conversion of the fuel gas to electricity and process heat using a conventional cogeneration system was employed at the pilot plant to demonstrate the utility of this product.

The HSAD effluent represents a product in which most biodegradable organics have been mineralized. A large portion of the feed solids are therefore removed from the process as a fuel gas. This results in an effluent that is lower in total solids and contains a high level of soluble and available nutrients for agricultural applications. The high operating temperature of the HSAD process $\left(140^{\circ} \mathrm{F}\left[\sim 60^{\circ} \mathrm{C}\right]\right)$ coupled with a solids retention time of 14 to 16 days ensures destruction of potential pathogens, weed seeds, and most viruses. The HSAD process effluent may be marketed directly as an organic compost and liquid fertilizer to plant nurseries, golf courses, local compost markets, or bulk agricultural markets.

The unit operations used in the the HSAD process are shown in Figure 2. This configuration provides for the greatest flexibility in the use of different feedstocks as well as the optimu marketability of the process effluent as both compost and liquid fertilizer.

With the success of early research efforts and the development of the intermediate-scale HSAD system, DOE contracted through NREL to design, permit, construct, install, commission, startup, and operate a pilot-scale demonstration of the technology.

During development of the HSAD technology at NREL, a technology application request was made to the DOE Pacific Site Office (Honolulu, Hawaii) by the island of American Samoa for technologies which would be appropriate for recycling the island's organic wastes. American Samoa, through the island's Territorial Energy Office (TEO), asked DOE to evaluate waste conversion technologies that could use both drier feedstocks like residential garbage and wetter wastes such as fish processing sludge while producing useful energy and byproducts for the island community. The DOE quickly identified the HSAD technology as the best fit for disposal 


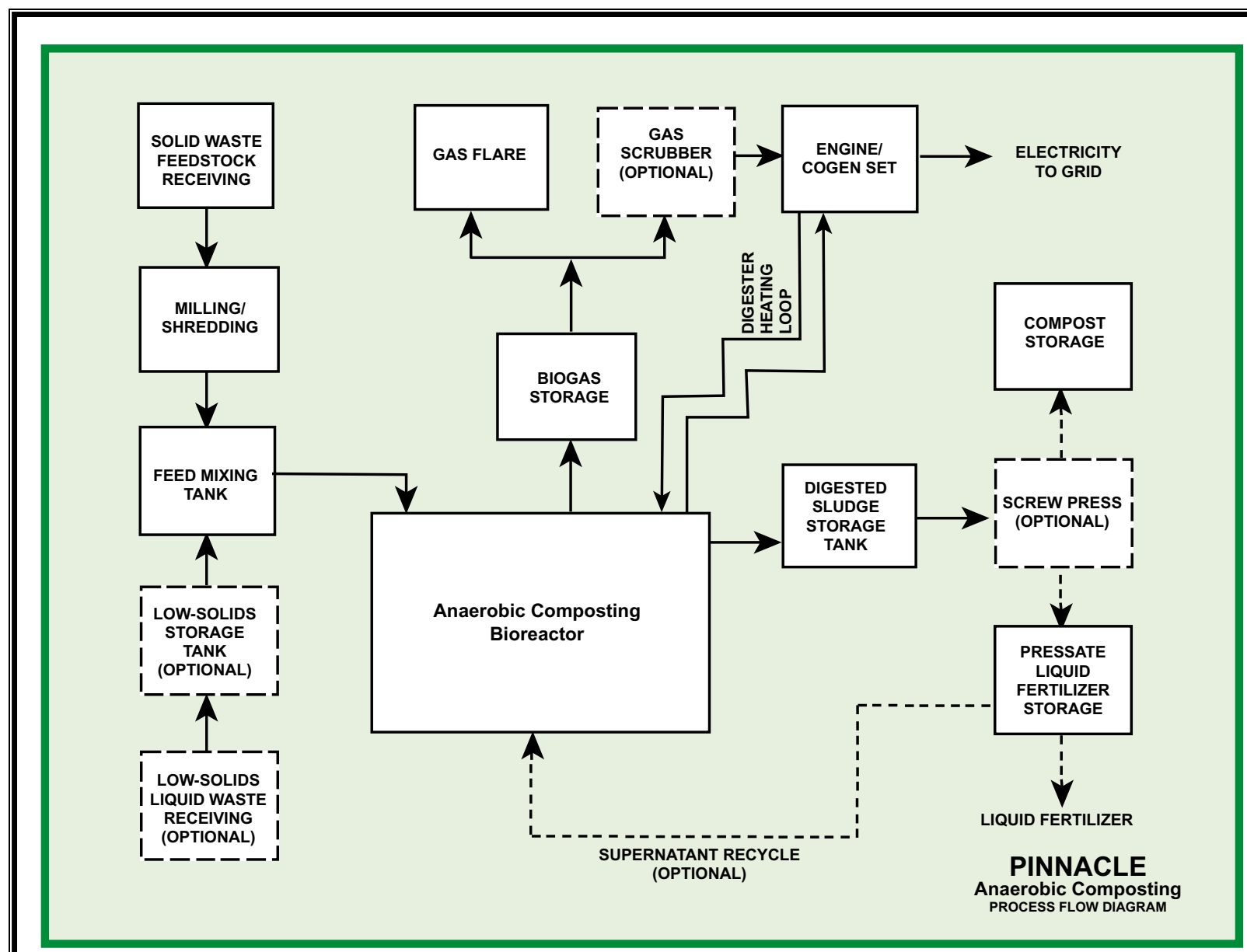

Figure 2. HSAD Process Block Flow Diagram

of their combined wastes. Several criteria used for selection of the HSAD technology include the higher water content of the fish sludges and relatively small volumes which made thermal conversion technologies less attractive. In addition to producing a fuel gas for on-island electricity production, the HSAD process also results in the production of an organic compost. American Samoa also demonstrated a great need for this byproduct to support their limited agricultural efforts and improve their soil which was mostly composed of volcanic ciders.

However, the HSAD technology had not as yet been demonstrated at commercial scale. A demonstration of the HSAD process at near commercial scale and using actual island wastes was envisioned. However, the remote location of American Samoa provided substantial obstacles in the demonstration of an emerging technology. Obtaining specific parts and equipment and maintaining technical personnel on-island were anticipated to be major impediments to testing the technology in American Samoa. It was therefore determined that pretesting the pilot demonstration system on the mainland US prior to relocating it to American Samoa would 
reduce risks and provide for a smoother operations phase by eliminating potential design and construction errors. A temporary testing site was chosen adjacent to a tuna fish processing plant in Terminal Island, CA. The site was a little-used warehouse near the Port of Los Angeles and owned by the Pan Pacific Fisheries company which supplied tuna processing sludge waste to the project. Later it was determined that moving the HSAD system to American Samoa would be both cost and time prohibitive and that a longer operating phase and more effective demonstration was possible by operating the pilot plant in the Los Angeles area only.

Development of the Pan Pacific Fisheries warehouse site had progressed to a limited extent including drafting of preliminary construction plans, investigating local permit requirements and precursory negotiations with Pan Pacific for long term warehouse use when the company entered into financial difficulties and faced bankruptcy proceedings. At this point, the Pan Pacific warehouse location was abandoned as being non-workable due to the unknown nature of the company's ownership and direction. A new location was offered by the project's other major waste feedstock partner, CR\&R, at a warehouse owned by them and very close to their material recovery facility (MRF) in Stanton, CA. A longer term lease for the Stanton site was negotiated and the project participants quickly renewed their efforts in developing the pilot system at this new site.

The DOE, through the NREL awarded a competitive contract to Bioengineering Resources, Inc. (BRI), of Fayetteville, Arkansas for the project implementation. BRI provided a team approach to bring the project to realization. This team included; Bioengineering Resources, Inc., Fayetteville, AR; Black \& Veatch, Kansas City, MO; Pinnacle Biotechnologies International, Inc., Golden, CO; US Filter/Envriex, Waukesha, WI; Esparza Fabrication, Westmorland, CA; and SCEC, Orange, CA.

During the early development stages of the project, NREL technical staff provided background technical information and mechanical system testing that were important to the design of the pilot scale system. Overall project oversight was the responsibility of BRI. Black \& Veatch was the lead group for the project design effort with input from NREL, BRI and Envirex. Project permitting was a shared responsibility between BRI, Black \& Veatch and SCEC. Pinnacle Biotechnologies International became involved in the project when, as the key researchers responsible for the development of the HSAD technology at NREL, they left to form their own company to better support the development effort. Pinnacle subcontracted with BRI to provide startup, operator training and on-site operations management of the project. Major equipment fabricators included US Filter/Envirex for the HSAD bioreactor and RMF for the feedstock mixing tank and feeding system. Esparza Fabrication was hired to provide site construction services by Black \& Veatch. Esparza also participated to a limited extent in plant commissioning. 
Major industrial participants included Pan Pacific Fisheries, Inc. (now Chicken of the Sea International, Inc.), Heinz Pet Products, Inc. and CR\&R, Inc. Chicken of the Sea and Heinz provided daily or as needed food processing wastewater sludges. The sludge produced by both companies were processed in a similar fashion using dissolved air floatation (DAF) technology to concentrate the organics as a sludge. These sludge wastes were therefore very similar in composition including total solids, volatile solids, and fat, oil and grease content. Both sludge wastes were hauled for disposal by the same transport company (i.e., Artesia Molasses) who was contracted by BRI to transport sludge to the pilot plant as feedstock.

The other major contributor was CR\&R, Inc. who provided sorted and shredded refuse. A shredder (provided by the project) was installed at the MRF in Staton, CA, directly below the manual sorting decking. MRF operators hand picked organic wastes from the conveyor belt and deposited the materials in a chute which lead to the shredder. Sorted and shredded waste was deposited in large nylon bags known as "super sacks." These filled sacks generally weighed from 200 to 400 pounds per sack and were moved using a wheeled cart and then a fork lift fro the MRF to a trailer for transport to the HSAD pilot plant.

A general project time line for the HSAD demonstration project is detailed in Table 1, below. Following the project kickoff meeting held at NREL in January of 1995, the project team made a trip to American Samoa to evaluate the logistics of operating a pilot plant at this remote location. Local siting and permitting requirements, waste feedstock transport and offtake product use and plant operations and maintenance needs were all evaluated. Potential on-island construction contractors and local support logistics were also analyzed. The general conclusion from this site visit was that the costs for demonstrating the HSAD technology in American Samoa would be substantially greater than originally anticipated. In addition, the remote location of American Samoa would reduce the potential for parties interested in the technology to visit and tour the facility. The final conclusion was that identical waste feedstocks including sorted/shredded MSW and tuna processing sludge could be obtained in Los Angeles where the HSAD system operating costs could be minimized to extend the operating phase of the project and provide for a location that was relatively accessible to most parties interested in the technology. 
Recycling and Energy Recovery Pilot Project

Table 1. Pilot Scale HSAD Project Time-Line

\begin{tabular}{|c|c|c|c|l|}
\hline \multicolumn{2}{|c|}{ Proposed } & \multicolumn{2}{c|}{ Actual } & \multirow{2}{*}{ Activity } \\
\hline \hline Start & End & Start & End & \\
\hline \hline $01 / 95$ & $01 / 95$ & $01 / 95$ & $01 / 95$ & DOE Contract Signed, Project Initiated \\
\hline $01 / 95$ & $09 / 95$ & $01 / 95$ & $09 / 95$ & $\begin{array}{l}\text { System design, equipment specifications and procurement, site construction } \\
\text { plans and initial permitting work for Terminal Island site }\end{array}$ \\
\hline--- & --- & $09 / 95$ & $09 / 95$ & Site changed to Stanton \\
\hline--- & --- & $04 / 95$ & $11 / 95$ & Site construction plans and permit preparation \\
\hline $09 / 95$ & $01 / 96$ & $11 / 95$ & $09 / 96$ & Permits and final construction plans approved \\
\hline $01 / 96$ & $03 / 96$ & $10 / 96$ & $02 / 97$ & Plant construction \\
\hline $03 / 96$ & $05 / 96$ & $02 / 97$ & $03 / 97$ & Plant commissioning \\
\hline $05 / 96$ & $05 / 96$ & $03 / 97$ & $03 / 97$ & Starter culture added to HSAD system \\
\hline--- & --- & $04 / 97$ & $07 / 97$ & System equipment modifications and retrofit completed \\
\hline $05 / 96$ & $07 / 96$ & $06 / 97$ & $09 / 97$ & Automated control system refined and brought on-line \\
\hline $05 / 96$ & $07 / 96$ & $07 / 97$ & $02 / 98$ & Lag time required for HSAD biocatalyst to reach “critical mass" \\
\hline $07 / 96$ & $06 / 98$ & $02 / 98$ & $05 / 98$ & Operating period commences, operating data obtained \\
\hline & & & $5 / 16 / 98$ & HSAD system idled due to funding exhausted \\
\hline
\end{tabular}

\section{Background}

Anaerobic digestion is a natural process in which a consortium of microorganisms work in synergy to convert complex organics to methane and carbon dioxide. The process occurs naturally in the sediments of lakes and rivers. The process also occurs in the gut of insects, animals and humans. In fact, the production of methane by termites and cows has been reported to be a major source of global warming.

The disposal of organic wastes by landfilling generally results in methane production as a consequence of anaerobic microorganisms digesting the wastes in the covered environment. The rate and yields of methane produced in landfills may vary considerably but are generally slow and incomplete owing to the uncontrolled nature of the environment. Due to inadequate inoculation, low temperatures and no mixing, anaerobic digestion in landfills may take hundreds of years to complete. Landfill emissions are a major contributor to the U.S. greenhouse gas inventory. 
The HSAD process was designed to take advantage of the microorganisms responsible for the conversion. In addition, the mechanical system used is designed to be simple, durable, and low cost, as the HSAD process must compete on an economic basis with other processes (i.e., landfilling) for organic waste disposal.

\section{The Microbial Engine.}

Organic wastes including MSW, agricultural residues, food processing wastes, industrial and packaging wastes, animal manure and sewage sludge are composed of polymers which must first be converted to soluble components prior to conversion to methane and carbon dioxide. It is this first hydrolytic step which is the rate limiting stage in the anaerobic digestion of most solid feedstocks.

Hydrolytic anaerobic microbes must expend valuable energy to produce enzymes which are the catalyst for this hydrolysis process. These anaerobes generally retain these enzymes on their outer surface and must therefore come in direct contact with the solid substrate before the enzyme is effective. This ensures that soluble hydrolysis products are first available to the hydrolytic microbe which produced the enzyme. Maintaining continuous contact between the hydrolytic microbe and the substrate thereby ensures the maximum rate of polymer breakdown.

Another limiting factor for the anaerobic process is that not all microbes are equally robust. The last two groups of microorganisms in the consortium which are involved in the conversion of short chain organic acids to methane and carbon dioxide endproducts, namely the acetogens and methanogens, are sensitive to even modest changes in their environment. Small changes in $\mathrm{pH}$, temperature, salt concentration or organic substrate or endproduct pools can inhibit the activity of these microbes. Protecting these microbes from changes in their environment is crucial to maintaining a stable and robust process.

Fortunately, these microorganisms have a propensity to produce films, that is a layering of microbes, especially where a synergistic relationship exists. This layering provides a gradient or buffering of the general environment to those microbes inside the film. This acts to protect microbes within the film from environmental changes, thereby enhancing the stability of the process. Microbial films have been used extensively in liquid waste conversion systems including anaerobic fixed film and anaerobic sludge blanket reactors to improve process rates and stability. In these systems, microbial films are encouraged by use of an inert support such as ceramic, glass, plastic or wood for microbes to attach and grow or by fostering the development of microbial granules. As anticipated, these systems are inherently robust and forgiving to environmental perturbations.

The anaerobic digestion process utilizes at least four distinct groups of microorganisms which act to convert organic polymers to the methane and carbon dioxide endproducts. The endproduct of one microbe is the feedstock for the next. Working together, the consortium of microbes act to 
"pull" the series of biological conversions to completion. The buildup of any one microbes' endproducts would inhibit the entire process. The production of microbial films provides the intimate and direct contact that is necessary for the microbial consortium to provide rapid transfer of carbon. The HSAD process focuses on employing a low shear form of mixing to maintain constant contact of hydrolytic microbes with their substrate and promote the formation of microbial films to enhance both the stability and reliability of the process.

The HSAD process also employs thermophilic, or high temperature microorganisms to achieve more rapid rates of organic waste conversion. These natural microbes, obtained from hot springs, have been adapted to grow under high solids (lower moisture) and high free ammonia conditions. Operation of the HSAD system at high temperature $\left(135^{\circ} \mathrm{C}\right.$ to $\left.140^{\circ} \mathrm{C}\right)$ ensures that the final compost and liquid fertilizer products are sanitary with respect to potential microbial pathogens, weed seeds and the majority of viruses due to the extended time (14 - 16 days) with which the organic waste feedstock materials are exposed to the high temperature.

Scale up efforts require collection and storage of process effluent from smaller scale HSAD systems for use as inoculum to initiate larger scale systems. The HSAD process effluent is robust and may be stored for long periods of time (up to several years) at room temperature without substantial loss in microbial viability.

Zonal-Mixed Plug-Flow Process Design.

Most mechanical fermentation systems are designed to provide a well mixed and uniform environment. In this way, heat, nutrients, and catalysts are known to be evenly distributed providing for uniform reaction kinetics. In order to accomplish this, most fermentation systems utilize a form of mixing which imparts high levels of shear. Mechanical agitation, gas mixing, hydraulic mixing or combinations tend to shear materials and separate microbes from their solid substrates. These mixing designs are generally employed on low-solids liquid systems and will not function well when the solids content approaches $5 \%$ to $8 \%$. Power requirements for conventional mixing systems can also be extremely energy intensive to maintain effective mixing at higher solids levels.

To mix solid substrates (i.e., $10 \%$ to $35 \%$ solids) as in the HSAD process, NREL previously evaluated those designs used to mix solids in industrial applications. The pharmaceutical, food and plastics industry all have developed mixing designs for thick or solid materials. However, most of these mixers including, paddle, plow, ribbon, and the like, impart substantial shear and work to uniformly mix the contents generally by lifting or pushing the solids. This type of mixing not only imparts shear and frictional heat, but also requires substantial power input. The fundamental understanding of the HSAD microbial engine established the need to maintain low shear while mixing the incoming feedstock to adequately inoculate the material. In addition, anaerobic sludge at high solids behaves like rising bread dough in which product fuel gas forms entrained pockets causing the sludge bed to grow (or rise) unless the gas is released. Mixing 
designs employed by the mining industry demonstrate nearly all of the desirable attributes including low shear and relatively low power requirements and therefore represent the best approach to mixing dense materials. This equipment is also designed to be durable and relatively simple.

Following a comprehensive review of agitator designs, mixing "quality," and power requirements, a modified pug mixer was developed $(2,20,25)$. The tine type agitator of the pug mill provides low shear, zonal mixing (rather than complete mixing), and low power requirements. The slow speed of agitation combined with the simple tine blades acts to gently push materials aside dramatically reducing shear, and thereby encouraging microbial fil formation. The tines also act to release the entrained gas pockets maintaining a low sludge bed level. Power requirements are minimized through the use of a gear reducer to provide low speed (fractional rpm) and high torque at the agitator shaft from a high speed small horsepower motor.

\section{Project Scope}

The primary objective in the development and operation of the pilot scale HSAD system was to validate the process rates and yields (confirming smaller scale studies) in advance of commercial applications for the technology. The project scope included the design, construction and operation of the demonstration scale HSAD process using actual residential refuse and food processing wastes. Defined objectives included providing comprehensive mass and energy balance data for the HSAD process operated under the following conditions:

- High solids conditions (feedstock solids levels of $25 \%$ to $55 \%$ )

- Thermophilic operation $\left(135^{\circ} \mathrm{C}\right.$ to $\left.140^{\circ} \mathrm{C}\right)$

- Organic Loading Rates of 20 to $25 \mathrm{gVS} / \mathrm{Ld}$

- Use of actual MSW and Food Processing Wastes

Smaller scale research demonstrated substantial success in the anaerobic conversion of cellulosic feedstocks such as MSW and agricultural residues using the HSAD system. In fact, earlier studies indicated substantial increases in yield over alternative, first-generation, European high solids anaerobic systems (7). Demonstrating equivalent or better performance at pilot scale would further strengthen commercial scale marketing efforts for the technology.

The scale up of emerging technologies must also address a variety of engineering issues relating to equipment specifications and integration. Several of the sub-systems used in the intermediate scale HSAD system required re-engineering for pilot scale demonstration. One example was feedstock loading to the digester. At intermediate scale, the feeder was located above the digester thereby allowing gravity feed addition to the system. In this configuration, the feeder and digester were both pressurized with the product fuel gas. At pilot scale, elevating the feeder was not possible. In addition, pressurization of the feeder with product fuel gas represented a 
safety hazard as well as loss of product fuel gas during feed preparation. An alternative feed system which was capable of isolating the digester from the feeder was evaluated at small scale using a conventional screw. Through small scale testing, it was determined that any section of pipe in which the screw did not extend into demonstrated the propensity to create a compacted plug subsequently disabling the feed system. In application at pilot scale, the screw feed syste worked well (with solid feed) providing an effective isolation point between the digester and feeder.

The pilot scale effort also focused on evaluating the suitability, durability and automated control of process equipment. Demonstrating the use of commercial automation hardware and software to improve process performance, provide enhanced reliability and safety, and reduce labor requirements provides increased process cost/benefits while reducing operational risks.

\section{Results}

\section{Design.}

The pilot plant design work was a joint effort involving Black \& Veatch, Envirex, BRI, and NREL. Researchers responsible for the development of the HSAD process at NREL provided general process performance and control information to the design team. Black \& Veatch played the key role in developing the proposed process mass balance calculations, the process and instrumentation drawings (P\&ID), the equipment layout and construction drawings, and equipment specifications. NREL staff, with assistance from Pinnacle Biotechnologies and Lone Tree Consulting, provided the computer control, automation and monitoring system.

An exhaustive safety review (HAZOPS) of the process design and control systems was conducted to reduce the level of risk in operating the system. The safety review also included evaluation of the daily facility operations to reduce risks to plant operators.

While the majority of the pilot plant equipment were considered off-the-shelf and were procured from major vendors, the HSAD bioreactor and feedstock mixing and addition systems were unique and their design was provided by specific vendors. Envirex (now US Filter/Envirex, Waulkesha, WI) was given generalized performance specifications for designing the HSAD bioreactor and associated systems. In addition, detailed information on the development of the HSAD mixing system and associated agitation requirements for the pilot scale HSAD bioreactor design based on intermediate-scale bioreactor experience was provided by NREL. Envirex also specified and provided the associated utility systems for the HSAD bioreactor. While early design work by Envirex was reviewed by the project team, Envirex was responsible for pretesting the HSAD bioreactor agitation system in their fabrication facility prior to shipping to the project site. The feedstock mixing and feeding system were designed and fabricated by RMF, Inc. (Kansas City, MO). The design used was a modification of a standard mixer used to blend meat for hamburger production. 
Black \& Veatch, Envirex and RMF were reported to be experts in their respective fields yet numerous minor and several major design errors lead to delays and additional costs for permitting, commissioning and startup of the HSAD system. While these design errors limited the effectiveness as well as the duration of the operations phase of the project they also provided an opportunity to develop alternative approaches to solids handling issues as well as system operations. Specific mechanical and operational issues are detailed below in a separate section.

\section{Permitting.}

Numerous permits were required to operate the pilot scale HSAD system. Local building and construction permits, regional air quality permits, fire, health and business permits and licenses were all required prior to the start of construction or initial operations. Investigation of permitting requirements for the initial Terminal Island site had progressed to a limited extent prior to the site change to Stanton. Initial discussions with the City of Stanton identified a normal permitting time frame of 9-months to 1-year. Because the technology was unique and new to the City of Stanton Officials, the feedstocks were unusual and the large quantities of fuel gas produced, the City took a conservative approach to permitting the plant. Actual time require for permitting approval was approximately 10 months.

The City of Stanton required the projects' primary contractor, BRI, to prepare a Land Use Review utilizing local planning and consulting firms which the City identified. Hogle-Ireland, Inc., Robert Bein, William Frost \& Associates, and The Planning Center were all interviewed as candidates. The Planning Center was selected and BRI contracted with them to provide a comprehensive report. The Planning Center provided a report which identified the research and development aspects of the pilot plant were permittable under the City's current codes.

The project's air permit application was prepared by SCEC (Orange, CA). Information on the projected fuel gas production and energy conversion equipment were prepared along with the potential direct impact of the plant's operation on the surrounding community. The project was granted a research and development permit with annual renewal.

The Orange County Fire Authority and the City of Stanton Health and Building Permits were prepared by BRI.

\section{Construction.}

Plant construction was contracted by Black \& Veatch Construction to Esparza Welding (Westmorland, CA). Development of the HSAD pilot plant involved using an existing warehouse structure to house the majority of the plant equipment. The 17,000 square foot building was first subdivided to create two distinctly different facilities. The smaller half of the building (approximately 8,000 square feet) was used for the HSAD pilot system. Major operations including feedstock receiving, feeding mixing, the HSAD bioreactor, utility systems, analytical laboratory, process control and operator and visitor areas were contained within the building. 
Fuel gas storage, the cogeneration system and flare and the effluent storage tank and screw press were located external to the building in the adjoining secured lot.

A variety of issues conspired to delay completion of construction including: repetitive changes to the construction drawings required by the City of Stanton, a lack of elevation drawings to adequately guide construction, which lead to rework by the construction contractor, a lack of investigation of the building's existing electrical power availability which required major upgrading, and a lack of commissioning and startup support. Early in the construction phase of the project it was discovered that the warehouse building was equipped with 208 Volt power only. Since much of the major equipment required 480 Volt power, a new power line, transformer, and power panel needed to be installed. Many of these issues were addressed during the project and could have been avoided with more ineffective management by the prime contractor and subcontractor. However, this experience will assure that future commercial scale project developments will not suffer such delays.

\section{Operator Training.}

Ten plant operators were selected from a local temporary staffing agency to provide manpower to monitor and operate the pilot HSAD system. The primary contractor, BRI, developed a staffing plan requiring 2 operators to be on duty at all times. Operators attended a 4-week training program which included detailed information on the roles and responsibilities of the job, the objectives and goals of the project, detailed information on pilot plant equipment, its installation, operation and maintenance, safety and health aspects, laboratory analytical equipment and procedures, and data collection, analysis and logging. Operators were also trained on specific equipment including forklift operation. Operator training was provided by BRI, Pinnacle Biotechnologies and outside consultants. All training was documented.

\section{Commissioning.}

The commissioning phase of the project was condensed and abbreviated due in part to delays in completing construction and the need to rapidly proceed to inoculation and startup. Major systems including the HSAD bioreactor and gas storage and use were integrity tested to ensure the safe handling of the product fuel gas. Individual tank load cells were tested for accuracy including the sludge feedstock storage tank (T-201), feedstock mix tank (T-301), the HSAD bioreactor (T-401) and the effluent storage tank (T-501). System temperature sensors were tested electronically. Motor controllers were also tested. Although much of the basic system testing was completed, some sensors and metering devices were never fully calibrated following installation. This was due to a lack of special calibration standards and equipment and the shortage of time and manpower required to fully complete commissioning. In retrospect, this could have been avoided with better planning on the commissioning phase of the project. 


\section{Inoculation.}

As described above, the HSAD system employs a unique consortium of thermophilic anaerobic bacteria. This "microbial engine" is unique in that it represents microbes obtained from nature which have been selected over a longer period of time to convert a wide variety of organics to fuel gas and compost under demanding conditions. The most rapid startup of the pilot scale HSAD system would involve adding a working volume of adapted HSAD consortium to the digester (32,000 liters). The minimum volume required to start the digester was 20,000 liters or $50 \%$ of the digester's volume. This is because sufficient sludge must be added to the digester to cover the feed addition port allowing an isolation point between the feeder and digester systems. The starting sludge volume could have been reduced if an alternative feed addition system was utilized which did not require a plug to be formed (i.e., positive displacement pump).

During previous HSAD development efforts at intermediate scale (1,000 liter digester), approximately 2,500 liters of active culture (sludge) was collected and stored for use in inoculating the pilot scale digester. This relatively small amount of starter culture was insufficient to provide the level necessary to startup the digester. Therefore, "filler sludge" was used to provide the added volume needed. The term "filler sludge" refers to anaerobically digested and dewatered sludge or biosolids obtained from a conventional wastewater treatment plant.

Essentially, sewage sludge or biosolids are composed of active anaerobic microorganisms and slow-to-degrade organics which have been centrifuged to remove excess water prior to disposal. This sludge contains valuable macro and micro nutrients, oxygen inhibiting components and provides a neutral buffering capacity. The vast majority of microbes in sewage sludge are destroyed when the sludge is heated to the HSAD operating temperature of $135^{\circ} \mathrm{F}$ to $140^{\circ} \mathrm{F}$. This added sewage sludge then simply acts as a "filler" with the proper environment for the outgrowth of the HSAD adapted culture.

Approximately $30,000 \mathrm{Kg}$ of filler sludge was obtained from the Terminal Island Wastewater Treatment Plant (Terminal Island, CA) under permit from the Los Angeles Sanitation District. The filler sludge was delivered in an open, live-bottom trailer and off loaded into super sacks at the pilot plant. The filler sludge was then loaded along with a small volume of adapted HSAD culture to the feedstock mix tank and loaded into the pilot digester. Because of the minor level of adapted HSAD inoculum available (in relation to the filler sludge), a substantial lag period was anticipated for the culture to reach critical mass. However, multiple mechanical complications conspired to dramatically extend this lag period.

First, the filler and adapted sludge was rapidly transferred from the feeder to the digester to avoid oxygen intrusion and prevent nuisance odors. Because of this rapid transfer, the feeder preheater was not able to adequately heat the sludge inoculum to the desired operating temperature. Without adequate preheating, the digester heating system was responsible for increasing the temperature of the inoculum to the operational temperature. However, HSAD bioreactor was 
designed with a relatively small heat exchanger surface area (i.e., hot water jackets units bolted along the bottom of the digester walls). This drastically slowed heat transfer to the sludge inside the digester. This problem was further compounded by the low level of mixing afforded by the HSAD agitator which reduced the heat transfer inside the digester. To further aggravate the problem, hot water was added to the digester to "thin the mix" in an effort to reduce torque loads on the agitator. Unfortunately, the hot water heater was not large enough to supply the quantity of hot water needed. Therefore, the addition of dilution water further reduced the temperature of the inoculum while providing a shock to the consortium through a rapid change in the solids level thus affecting the salt concentration. Further problems with the agitator drive system required removal of the inoculum from the digester to a tanker truck while changes to the digester agitator blades were made. In an effort to further reduce torque loads on the agitator, approximately one half of the agitator tines were removed. The remaining tines were realigned to maximize the potential zonal mixing in the bioreactor. The transfer and temporary storage of inoculum in the tanker truck further reduced the temperature of the sludge while also allowing oxygen to potentially inhibit the consortium. These problems were a direct result of the agitator system not being designed to meet the performance specifications.

\section{Startup.}

The HSAD system startup phase is defined here as the time required immediately following inoculation of the bioreactor to the point at which the system had reached critical mass and was capable of processing increased organic loadings without substantial deterioration in process performance. The initial pilot plant startup phase followed a predictable number of mechanical, operational and control problems as may be encountered for emerging technologies. The majority of these problems, while slowing the startup phase of the project, were rapidly corrected. The specific mechanical and operational issues encountered are discussed below in a separate section. Immediately following the addition of the inoculum to the digester, the system was allowed to remain unmixed until several volumes of fuel gas were produced to sweep out any remaining air. When the agitation system was started it would not mix the contents of the digester. As previously mentioned, the root cause was identified as an error in the original design specifications of the agitation drive system. Several attempts were made to reduce the torque requirements including dilution of the sludge with domestic hot water, reduction of the sludge volume, and recirculation of the digester sludge using the effluent pump. For a total compilation of the problems and activities during the initial startup period see Table 2 . 
Recycling and Energy Recovery Pilot Project

Table 2. Operational Issues Relating to Initial Plant Startup

\begin{tabular}{|c|c|c|}
\hline Date & Problem & Activity \\
\hline $3-27-97$ & None & Inoculum added to pilot digester \\
\hline $3-30-97$ & $\begin{array}{l}\text { No Mixing } \\
\text { Low Digester Temperature }\end{array}$ & Agitator drive system non-operational \\
\hline $4-2-97$ & $\begin{array}{l}\text { No Mixing } \\
\text { Low Digester Temperature } \\
\text { Sludge Solids Dilution }\end{array}$ & Dilution water added to digester to "thin-the-mix" \\
\hline $4-4-97$ & $\begin{array}{l}\text { No Mixing } \\
\text { Low Digester Temperature } \\
\text { Sludge Solids Dilution }\end{array}$ & $\begin{array}{l}\text { Additional dilution water added to digester } \\
\text { Digester sludge recirculated from back end to front end using } \\
\text { Moyno effluent pump }\end{array}$ \\
\hline $4-14-97$ & $\begin{array}{l}\text { No Mixing } \\
\text { Low Digester Temperature } \\
\text { Sludge Solids Dilution } \\
\text { Reduced Inoculum Volume }\end{array}$ & $\begin{array}{l}\text { Effluent pump recirculation continues } \\
\text { Reduced sludge level in digester, removed 3,500 liters of sludge to } \\
\text { effluent tank } \\
\text { Additional dilution water added to digester }\end{array}$ \\
\hline $4-19-97$ & Low Digester Temperature & Agitator mixes \\
\hline $4-20-97$ & $\begin{array}{l}\text { No Mixing } \\
\text { Low Digester Temperature }\end{array}$ & Agitator Stops \\
\hline $4-24-97$ & $\begin{array}{l}\text { No Mixing } \\
\text { Low Digester Temperature }\end{array}$ & Agitator Gear box removed for repair \\
\hline $4-29-97$ & Low Digester Temperature & Repaired gear box installed, Agitator mixing \\
\hline $4-30-97$ & $\begin{array}{l}\text { No Mixing } \\
\text { Low Digester Temperature }\end{array}$ & Agitator stops \\
\hline $5-8-97$ & $\begin{array}{l}\text { No Mixing } \\
\text { Low Digester Temperature }\end{array}$ & Agitator gear box removed for repair \\
\hline $5-17-97$ & $\begin{array}{l}\text { No Mixing } \\
\text { Low Digester Temperature } \\
\text { Sludge Exposed to Air }\end{array}$ & $\begin{array}{l}\text { Digester sludge transferred to tanker truck } \\
50 \% \text { of agitator tines removed }\end{array}$ \\
\hline $5-18-97$ & $\begin{array}{l}\text { No Mixing } \\
\text { Low Digester Temperature } \\
\text { Sludge Exposed to Air }\end{array}$ & Sludge transferred from tanker truck back to digester \\
\hline $5-20-97$ & Low Digester Temperature & Repaired agitator gear box reinstalled, Agitator mixing \\
\hline $5-23-97$ & Low Digester Temperature & Start digester feed introduction \\
\hline $5-24-97$ & Low Digester Temperature & Feed addition problems - boot broke \\
\hline $5-29-97$ & Low Digester Temperature & Feed auger jammed \\
\hline $6-12-97$ & $\begin{array}{l}\text { No Mixing } \\
\text { Low Digester Temperature }\end{array}$ & Agitator hydraulic power system fails \\
\hline
\end{tabular}


Recycling and Energy Recovery Pilot Project

\begin{tabular}{|l|l|l|}
\hline 6-14-97 & Low Digester Temperature & New agitator gear drive installed, system up and running \\
\hline 6-20-97 & $\begin{array}{l}\text { Intermittent Mixing } \\
\text { Low Digester Temperature }\end{array}$ & Agitator stopped temporaril \\
\hline $7-1-97$ & Low Digester Temperature & $\begin{array}{l}\text { Need for lower solids in feed and dilution water addition to } \\
\text { digester to maintain thin mix and allow continuous agitation }\end{array}$ \\
\hline
\end{tabular}

During this initial 3-month period, it became evident that major modifications to the agitation system were required in order to achieve mixing in the digester system. Reducing the number of agitator tines, reducing the sludge solids level through routine addition of dilution water and the addition of a larger agitator gear motor all helped to reduce the mixing problem. While the time spent to alleviate the mixing problems delayed actual operation, this period of time was used to further train (and thus better prepare) the pilot plant operators for normal operations. Using actual process samples, the operators were trained on proper sampling procedures, laboratory protocols and analysis, plant data collection, computer control system monitoring, and equipment problem solving. The operators' analytical capabilities were improved during this time to provide relatively reliable accuracy. In addition, plant equipment maintenance and housekeeping activities were refined to provide a safe and orderly plant environment. Many daily procedures including data logging and archiving were refined or expanded from their original development.

During this initial period of equipment modifications (April thru June), plant data were collected and logged, but, due to the nature of the operation, the data were not representative of the actual system performance. Startup data were initiated July 1, 1997 as the digester agitation system and feed introduction system were basically on line.

Lag Phase Data. During the period of July 1, 1997 to approximately July 18, 1997 the temperature in the HSAD system had not fully reached the desired set point of $135^{\circ} \mathrm{F}$ to $140^{\circ} \mathrm{F}$. Therefore, the mesophilic (lower temperature) microbes from the added filler sludge were still active. Feedstock added to the digester was rapidly degraded with close to $100 \%$ conversion efficiency (see Figures 3, 5). Gradually, the temperature of the HSAD bioreactor reached the desired setpoint through addition of preheated feedstock, continual (although slow) heat input from the digester heat exchangers and better distribute the heat with the digester by operation of the agitation system. As the temperature of the digester sludge reached the thermophilic set point, the mesophilic microbes in the filler sludge that had been active, were destroyed. At this point, the temperature was now conducive to outgrowth of the thermophilic HSAD starter culture. However, by this time, the starter culture had been exposed to air, diluted with water, and reduced in volume (sludge removed from the digester). The period of July 18, 1997 to August 12, 1997 demonstrated the die off of the filler sludge microbes evidenced by a dramatic reduction in the overall anaerobic conversion of added feedstock and a substantial drop in product fuel gas methane content (see Figures 4, 5). 
The anaerobic consortium is made up of diverse groups of microbes which demonstrate different rates of growth, metabolic activity, and tolerance to environmental changes. Generally, the hydrolytic microbes which participate in the initial hydrolysis of polymeric feedstocks to soluble organic acids demonstrate fast growth rates and high tolerance to environmental changes. Often when an anaerobic consortium has not reached critical mass, added feedstock will be efficiently hydrolyzed to organic acids while the further conversion of organic acids to the fuel gas products are slowed. This often results in a buildup of intermediate organic acids which drive the $\mathrm{pH}$ into the acid range further inhibiting the slow growing and sensitive acetogens and methanogens. However, the filler sludge provides substantial buffering capacity and early effluent $\mathrm{pH}$ data indicate no major changes (see Figure 8).

The buildup of intermediate organic acids can inhibit the microbial consortium thereby slowing progress toward attaining a critical mass. The remedy for this condition was to reduce additional feed to the process. From August 12, 1997 to September 23, 1997 the organic loading rate was maintained at nominal values of 1 to 2 grams volatile solids per liter sludge per day. During this time, the anaerobic conversion was generally below $50 \%$ while the product fuel gas methane content recovered to acceptable levels (see Figure 4). Occasionally, the organic loading was increased to almost $4 \mathrm{gVS} / \mathrm{Ld}$ in order to determine if the system would respond favorably to additional loadings. However, in these instances the conversion rate remained low and the fuel gas methane content dropped substantially (see period of September 15, 1997 to September 20, 1997, Figures 4, 5) indicating the consortium had not reached critical mass and was not capable of complete conversion.

The organic loading rate was maintained for an additional period of time (September 23, 1997 to November 10,1997) at a nominal $1-2 \mathrm{gVS} / \mathrm{Ld}$ whereby the consortium appeared to be approaching critical mass as the anaerobic conversion climbed to $75 \%$ of expected and fuel gas methane content consistently was greater than $50 \%$. However, high sludge free ammonia levels caused a further disruption in the operation of the system.

High Free Ammonia Levels. It is presumed that with the building of the microbial populations and greater metabolic activity, the large amount of cellular protein contained in the filler sludge was anaerobically digested resulting in high free ammonia levels in the digester. Previous HSAD studies at laboratory and intermediate scale demonstrated that the anaerobic consortium could be adapted to free ammonia levels as high as $5000 \mathrm{ppm}(0.5 \%)$ without inhibition. However, pilot scale free ammonia levels topped out at 10,000 ppm (1.0\%) on or about September 28, 1997. This concentration of free ammonia is surely inhibitory and a change in the composition of the feedstock was initiated to increase the $\mathrm{C} / \mathrm{N}$ ratio. The MRF feedstock was modified to contain only paper and cardboard from the period of September 231997 to January 5, 1998 (see Figure 12, high feedstock total solids) in order to reduce the nitrogen content of the combined feed (see Figure 16), and following feed introduction to the digester, dilute the sludge free ammonia concentration (see Figure 10). Indeed, over the period of September 20, 1997 to 
December 20, 1997, the digester sludge free ammonia concentration was reduced 10-fold to noninhibitory levels (see Figure 10).

pH Imbalance from Changing Food Waste Feedstock. During the end of December 1997, the project's food processing partner, Heinz Pet Products, curtailed operations for several weeks while yearly maintenance and plant improvements were instituted. The project then switched to using food processing sludge from Chicken of the Sea International (formerly Pan Pacific Fisheries). This tuna-based DAF feedstock was not $\mathrm{pH}$ adjusted during processing as the Heinz sludge was and therefore maintained a substantially lower $\mathrm{pH}$. Initial use of this low $\mathrm{pH}$ feedstock combined with essentially paper and cardboard MSW resulted in a combined feedstock with a pH of approximately 5.0 (see Figure 14, December 20, 1997 to January 13, 1998). The HSAD system did not respond well to continuous feeding of a low $\mathrm{pH}$ feedstock and demonstrated low digester effluent $\mathrm{pH}$ (see Figure 8), a substantial drop in fuel gas methane content (see Figure 4), and a major drop in anaerobic conversion (below 25\%, see Figure 5). During this time of low conversion, the digester total and volatile solids levels increased consistent with the low digestion rates (see Figures 6, 7). On January 15, 1998 the project began adding solid hydrated lime to the mix tank to buffer the combined feedstock to an acceptable $\mathrm{pH}$. Initially, the combined feedstock was buffered to a $\mathrm{pH}$ of $8-9$ in order to more rapidly affect the internal $\mathrm{pH}$ of the digester. Later, sufficient lime was added to provide a combined feedstock $\mathrm{pH}$ of 6.5 to 7.5 . Shortly after beginning the $\mathrm{pH}$ adjustment of the combined feedstock, the HSAD system recovered, demonstrating increased anaerobic conversion and fuel gas methane content. The digester sludge total and volatile solids content also decreased with improved anaerobic conversion. By February 20, 1998, consistent anaerobic conversion yields and fuel gas methane content indicated the system was in fact stable and the HSAD consortium had reached critical mass.

\section{Operations Phase.}

With recovery of the digester sludge free ammonia to acceptable levels (i.e., below 4,000 to 5,000 ppm), an all out push was initiated to build operating process data at higher organic loading rates. However, the incorrectly designed agitator drive system significantly restricted the operating phase of the project.

System Operating Restrictions. Because of project funding and time restrictions, at 11-months into the project, the operation of the HSAD system was still limited by the torque capability of the digester agitator. Early retrofitting of the agitator gear motor was limited by the shaft diameter which had been reduced during initial fabrication to accommodate a smaller gear motor as specified by the vendor. Therefore, the largest gear motor which could be safely used with the small diameter of the shaft required that the agitator torque load be maintained below $4000 \mathrm{ft} / \mathrm{lbs}$. In order to maintain this low agitator torque, the sludge solids level within the digester needed to be controlled at $15 \%$ solids or less (as compared to the desired solids level of $25 \%$ to $30 \%$ ). To accomplish this, the combined feed was prepared daily at approximately $30 \%$ solids (as compared to the desired $40 \%$ to $50 \%$ solids level). In addition, the feedstock entering the digester was 
further diluted with an equivalent volume of dilution water. The addition of substantial quantities of liquid served to hinder the reliability of the system equipment and reduce the fermentation performance of the HSAD process.

Substantial problems were encountered with the reliability of the digester feeding system as a result of the need to dilute the feedstock and digester sludge. The MSW and food sludge were combined in the mix tank to achieve a feedstock solids level of from $25 \%$ to $30 \%$ solids. At this solids level, small amounts of liquid would weep from the feed in the mix tank. This liquid seeped from the mix tank packing glands, requiring nearly continual cleaning in order to maintain a neat and odor free environment. In addition, this weeping liquid also drained from the mix tank into the feed screw. Considerably greater volumes of liquid drained from the digester itself down the feed screw.

While anaerobic sludge in the HSAD system demonstrates a greater capacity to bind liquid, dilution water added to the front end of the digester resulted in sludge solids levels of $12 \%$ to $15 \%$ which readily weep liquid. A substantial volume of liquid continually drained from the digester down the feed screw to its lowest point. Liquid draining back from the digester into the feed screw was also hot as a consequence of moving through the preheater. The combined liquid from the digester and mix tank collected at the lowest point of the feed screw, directly below the feed boot. This liquid would often create a slurry with the gravity-fed feedstock and because of the angle and design of the feeder system, the feed screw would be unable to effectively move this material. Unable to move the slurry in the lower feed screw, together with the continued addition of new feed to the screw by the mix tank auger, a feed plug would be created in the feed boot which would disable the entire feed addition system.

Often a backup in the feed boot would cause a hard pack to be created in the mix tank auger. Restarting the feed system required substantial disassembly and cleaning of the feed boot and mix tank auger as well as force feeding the screw auger by hand with a dry paper/cardboard feedstock until excess liquid was bound and feed movement resumed. A drain, located at the lowest point of the feed screw was opened and used to continuously drain off excess liquid in an attempt to reduce feed problems. However, small feed solids would intermittently plug this drain and the subsequent buildup of liquid in the feed screw would again disable the feed system. Routine clearing of the screw drain and recycling of drained liquid to the mix tank was required to provide relatively reliable operation of the feeder system. An alternative design for the feed addition system, in which the mix tank would be somewhat elevated as compared to the feed port of the digester, would reduce or eliminate the chances of liquid draining back from the digester. However, operating the HSAD system at the design solids level would have prevented these problems altogether. 
The addition of large volumes of liquid also reduced the fermentation performance of the system. The HSAD process operates best with a minimal amount of water. Use of relatively dry feedstocks approaching 55\% total solids enhances the level of organics conversion by increasing the solids residence time within the digester. As depicted in Figure 17, reducing the feedstock solids concentration acts to reduce the solids retention time in the digester. Working with a cellulosic feedstock like MSW, a minimum retention time of 14 to 16 days is necessary to achieve a conversion of $60 \%$ or better. As shown in Table 3 below, increasing the level of water in the digester to maintain low agitator torque loads restricted the HSAD system to an organic loading rate of $10 \mathrm{gVS} / \mathrm{Ld}$ without reducing the solids retention time significantly below the minimum 14 days.

As Table 3 depicts, use of a relatively dry feedstock with a properly designed mixing syste should theoretically allow organic loading rates approaching $35 \mathrm{gVS} / \mathrm{Ld}$ to be attained without reducing the solids retention time below the minimum 14 days.

\section{Table 3. Effects of Feedstock Dilution and Process OLR on the Theoretical HSAD Solids Retention Time*}

\begin{tabular}{|c|c|c|c|c|c|c|}
\hline \multirow{2}{*}{$\begin{array}{c}\text { Combined Feedstock } \\
\text { TS (mass\%VS) }\end{array}$} & \multicolumn{5}{|c|}{ Combined Feedstock Organic Loading Rate (gVS/Ld) } \\
\cline { 2 - 7 } & $\mathbf{1 0}$ & $\mathbf{1 5}$ & $\mathbf{2 0}$ & $\mathbf{2 5}$ & $\mathbf{3 0}$ & $\mathbf{3 5}$ \\
\hline \hline $55 \%(49.5 \%)$ & $49.5 \mathrm{~d}$ & $33.0 \mathrm{~d}$ & $24.8 \mathrm{~d}$ & $19.8 \mathrm{~d}$ & $16.5 \mathrm{~d}$ & $14.1 \mathrm{~d}$ \\
\hline $45 \%(40.5 \%)$ & $40.5 \mathrm{~d}$ & $27.0 \mathrm{~d}$ & $20.2 \mathrm{~d}$ & $16.2 \mathrm{~d}$ & $13.5 \mathrm{~d}$ & \\
\hline $30 \%(27.0 \%)$ & $27.0 \mathrm{~d}$ & $18.0 \mathrm{~d}$ & $13.5 \mathrm{~d}$ & & & \\
\hline $15 \%(13.5 \%)$ & $13.5 \mathrm{~d}$ & 90 & 6 & & & \\
\hline
\end{tabular}

*Retention time data given in days (d). Cross-hatched areas depict solids retention times significantly below the minimum 14 days resulting in lower HSAD feedstock conversions.

The volumes of water added to the HSAD feedstock in order to overcome deficiencies in the agitation system also served to dilute the concentration of mineralized fertilizer components for the compost/liquid fertilizer product. Diluting the fertilizer components reduces the value and marketability of both the compost and liquid fertilizer products following separation.

Logistical problems were encountered in storage and transport of the process effluent. Because of the need to dilute the HSAD effuent to $5 \%$ to $8 \%$ solids (see Figure 6 ) for pumping and tanker transport, the volumes of effluent to be handled increased dramatically. The effluent tank was specified with a 14,000 liter total volume (13,500 liter working volume) and as the process 
organic loading rate was increased, the number of transport hauls per week increased. At organic loading rates of 10 to $16 \mathrm{gVS} / \mathrm{Ld}$, an effluent pickup was required every 3 to 4 days. Often, the transport vehicle could not meet the plant's schedule and the HSAD process feeding was slowed or interrupted temporarily until a tanker truck was available to offload product from the effluent tank.

Process Control and Automation. The HSAD process Data Acquisition and Control System (DACS) was designed to automate feed addition to the digester, gas conversion to electricity and heat, and digester effluent removal. Control strategies were refined and improved during the startup period to provide a high level of accuracy and reliability. DACS process information and control was compared to manual data collection and monitoring performed by plant operators. Good agreement was determined for both manual and DACS process data. The DACS automated plant operations including feed addition, cogen operation, and digester level worked exceptionally well with the exception of specific reoccurring equipment problems. The DACS operation was made more robust through limiting operator interaction with program elements and increasing the level of system alarms. A daily report form was developed to provide a simple means of acquiring an average for many of the important process data points. The DACS was programmed to provide the daily report automatically every 24 hours. All DACS plant data including the daily report was stored in electronic files for later recovery and analysis. Plant data files were archived on removable floppy discs for safeguarding. Plant data was averaged and trends evaluated using graphical software. During operation of the pilot plant, process data was graphed and posted at the plant for operators to become familiar with data variability and trending.

Operating Phase Data. Previous smaller scale data identified a methane yield of $0.33 \mathrm{~m}^{3} \mathrm{CH}_{4} / \mathrm{kg}$ VS added per day for a combined feedstock of sorted and shredded MSW and food processing sludge (7). This value was used as representing the maximum effective level of anaerobic conversion possible in the HSAD process. The actual pilot plant process data were therefore compared to this anticipated yield.

Obtaining HSAD process data at increasing organic loading rates is normally addressed through a step-wise approach. The organic loading rate is increased in relatively modest steps of 1 to 4 $\mathrm{gVS} / \mathrm{Ld}$. After an increase in the OLR, the process is expected to demonstrate increased product gas production. A period of 1 to 2 retention times is normally required for the process rates to reach steady state. During this period, microbial populations adapt in different ways to the increased rate of feed introduction.

Generally, immediately following an increase in the OLR, a small level of anaerobic fermentation imbalance will occur for a short period of time. This imbalance is manifested by a slight drop in fuel gas methane content, an increase in intermediate organic acid pools, and a slight increase in effluent total and volatile solids. In some cases, and depending on the buffering capacity of the digester sludge, a slight reduction in sludge $\mathrm{pH}$ may also occur. As the digester consortium 
responds to the increase in OLR through greater microbial populations, all of the fermentation parameters return to their most stable levels.

During the operating phase of the pilot project, we were unable to maintain a consistent OLR for greater than 7 days at a time (see Figure 18). Multiple problems were encountered which adversely affected our ability to prepare sufficient quantities of feedstock, reliably introduce the feedstock to the digester, remove sludge from the digester and unload effluent from the effluent tank. During the period of April 14, 1998 to April 23, 1998 a major problem was encountered with one of the mix tank's mixer motors and gear boxes. These problems allowed the HSAD system to be operated only under relatively unstable conditions.

Despite the lack of maintaining discreet OLRs over a longer period of time, the HSAD data collected provide a "snap-shot" of the process' capability. Summarized data are detailed in Table 4 below and indicates that at OLRs of 5 to $14 \mathrm{gVS} / \mathrm{Ld}$, the overall conversion was generally greater than $80 \%$ of the expected yield.

Table 4. Pilot Scale HSAD Operating Phase Data

\begin{tabular}{|c|c|c|c|c|}
\hline \multicolumn{2}{|c|}{$\begin{array}{c}\text { Organic Loading Rate* } \\
\left(\mathrm{KgVS} / \mathrm{m}^{3} \bullet \mathrm{d}\right)\end{array}$} & \multirow[t]{2}{*}{$\begin{array}{c}\text { Methane Yield } \\
\left(\mathrm{m}^{3} \mathrm{CH}_{4} / \mathrm{KgVS} \text { fed॰d) }\right.\end{array}$} & \multirow[t]{2}{*}{$\begin{array}{l}\text { \% Conversion } \\
\text { (based on VS) }\end{array}$} & \multirow[t]{2}{*}{$\begin{array}{l}\text { Number Data } \\
\text { Points (Days) }\end{array}$} \\
\hline Target & Actual & & & \\
\hline 5 & 5.14 & $0.266 \pm 0.187$ & 80.75 & 3 \\
\hline 6 & --- & --- & --- & 0 \\
\hline 7 & 7.47 & $0.348 \pm 0.052$ & 105.42 & 4 \\
\hline 8 & 8.65 & $0.268 \pm 0.060$ & 81.12 & 4 \\
\hline 9 & 9.58 & $0.296 \pm 0.073$ & 89.81 & 12 \\
\hline 10 & 10.50 & $0.290 \pm 0.062$ & 87.93 & 11 \\
\hline 11 & 11.54 & $0.249 \pm 0.056$ & 75.56 & 11 \\
\hline 12 & 12.55 & $0.272 \pm 0.060$ & 82.50 & 6 \\
\hline 13 & 13.03 & 0.259 & 78.41 & 1 \\
\hline 14 & 14.42 & $0.265 \pm 0.033$ & 80.34 & 4 \\
\hline
\end{tabular}

* The target organic loading rate represents the operating setpoint entered into the Gensym G2 control system. The actual organic loading rate was different based on daily changes in the HSAD bioreactor volume, feedstock delivery variation, and the need to add dilution water to the digester system to maintain low agitator torque levels for operation. 
The specific average anaerobic conversion yield was $0.279( \pm 0.030) \quad{ }^{3} \mathrm{CH}_{4} / \mathrm{kgVS}$ with a product fuel gas methane content of $57.4 \%( \pm 2.1)$. The average sludge solids on exit of the digester was $13.7 \%( \pm 2.1)$ total solids, $81.1 \%( \pm 2.2)$ volatile solids (of the TS), and had a $\mathrm{pH}$ of $7.5( \pm 0.3)$. The average digester operating temperature was $55.9^{\circ} \mathrm{C}( \pm 1.4)$ with a system gas pressure of approximately 13 inches of water column $(0.47 \mathrm{psi})$. The operating phase data demonstrated exceptional resiliency to changing OLRs with good immediate (first $24 \mathrm{hr}$ ) conversion yields.

As described above, the HSAD system was operated under a variable OLR which results in process data which represents a system in transition and does not fully represent the true process conversion rates or yields. It is therefore highly likely that with a correctly designed agitator, and operating the HSAD bioreactor at a consistent OLR over a 2 to 3 retention time period, that anaerobic conversion yields obtained would be equivalent or greater than that determined previously in smaller scale HSAD system tests.

Mass Balance Calculations. The lack of sufficient operating time coupled with the lack of OLR control, reduced the data available for calculating the mass balance for the process. In addition, difficulties were encountered in accurately calculating the volatile solids reduction for the HSAD process. Inaccuracies in monitoring dilution water addition (both at the digester and prior to the effluent tank) coupled with a lack of adequate mixing in the effluent tank which lead to float layers, reduced the ability to effectively determine the true volatile solids content of the process effluent. The effluent volatile solids content was therefore calculated based on the ash content of the mix tank feedstock since the ash content was assumed to remain constant through the process.

The calculated level of volatile solids destruction (reduction) is described below in Table 5. The data indicates a range of $44 \%$ to $55 \%$ VS conversion depending on the source of the effluent sample. Sample inaccuracies include a low level of mixing and incomplete solids retention time for Pinch Valve Sample \#4 and inadequate mixing and float layer formation for the effluent sample.

\section{Table 5. Comparison of Calculated VS Destruction and Mass Balance Closure with Effluent Sampling Source}

\begin{tabular}{|l|c|c|c|}
\hline Data Source & Data Interval & $\begin{array}{c}\text { Calculated VS } \\
\text { Destruction* }\end{array}$ & $\begin{array}{c}\text { Mass Balance } \\
\text { Closure** }\end{array}$ \\
\hline \hline Pinch Valve \#4 & $3 / 13 / 98$ to $5 / 15 / 98$ & $44.92 \%$ & $92.63 \%$ \\
\hline Effluent Tank & $3 / 14 / 98$ to $5 / 15 / 98$ & $55.08 \%$ & $75.54 \%$ \\
\hline
\end{tabular}

* Based on normalization for feedstock ash content.

** Based on 0.856 liters of biogas per gVS converted. 
The mass balance closure for the process data was calculated based on the production of 0.856 liters of biogas per gram of volatile solids converted or destroyed. The process mass balance varied between $75.5 \%$ and $92.6 \%$ based on the source for process volatile solids destruction used.

Energy Balance Calculations. It was anticipated that calculating the process energy balance would be relatively meaningless in regards to the true parasitic loads for commercial scale plants due to the extremely small scale of the demonstration plant. Many of the utility and support systems including the DACS, computer control, office, laboratory, plant lighting, compressed air, hydraulic system, domestic hot water, ventillation, and environmental monitoring systems would be nearly the same for the demonstration as well as substantially larger commercial scale systems. In addition, smaller cogeneration systems are not as efficient as larger systems in converting biogas Btu's into electrical power. However, the major difficulty in obtaining meaningful power usage and production data focused on the cogen system itself. The cogen was unable to faithfully start and operate at its maximum electrical output with digester gas with a methane content of less than $60 \%$. In addition, the cogen system was specified with a heat recovery system with a maximum operating temperature below that which was necessary to meet the heating requirements for the HSAD system due to the minimal design of the heat tracings of the digester. The backup hot water heater was therefore used exclusively to maintain heat in the digester and the feedstock preheater.

Table 6 projects the parasitic electrical power requirements for the HSAD process based on the theoretical fuel gas production and conversion to electricity at the target OLR of $20 \mathrm{gVS} / \mathrm{Ld}$. These data indicate that if the cogen was properly specified to provide the required heat for the HSAD process and more efficient feedstock mixing motors were employed, a parasitic load of

Table 6. Calculated HSAD Plant Parasitic Load Based on Process Operations

\begin{tabular}{|l|c|c|c|}
\hline System & $\begin{array}{c}\text { Plant Use } \\
\text { (kwh/month) }\end{array}$ & $\begin{array}{c}\text { Calculated Plant } \\
\text { Production* } \\
\text { (kwh/month) }\end{array}$ & $\begin{array}{c}\text { Calculated } \\
\text { Parasitic Load }\end{array}$ \\
\hline \hline As Operated & 21,164 & 21,600 & $98.0 \%$ \\
\hline $\begin{array}{l}\text { Eliminate Digester Hot Water } \\
\text { Heater }\end{array}$ & 14,684 & 21,600 & $68.0 \%$ \\
\hline $\begin{array}{l}\text { Eliminate Digester Hot Water } \\
\text { Heater and Reduce Mixer } \\
\text { Motor Size by Half }\end{array}$ & 9,315 & 21,600 & $43.1 \%$ \\
\hline
\end{tabular}

* Based on OLR of $20 \mathrm{gVS} / \mathrm{Ld}$; 32,000 liter digester working volume; 35\% TS combined feedstock; 17.5 day retention time; $0.33 \mathrm{~m}^{3} \mathrm{CH}_{4} / \mathrm{Kg}$ VS fed; cogen electrical efficiency of $33 \%$; continuous operation of a $30 \mathrm{kw}$ cogen. 
about $43 \%$ would be expected. Additional improvements are expected at commercial scale such that the parasitic load would be on the order of $15 \%$ to $20 \%$ of electrical production. The parasitic heat load is estimated at $20 \%$ to $25 \%$ of the cogen heat output.

\section{Conclusions}

Major project objectives in the development and verification of the HSAD process at pilot scale were achieved including use of actual MSW and food processing wastes, operation with high solids feedstocks, thermophilic operation and high organic loading rates. In addition, the pilot plant was operated successfully in a light industrial area, under close scrutiny by business neighbors with a high level of approval. While initial plant permitting was a protracted process, the overall effect was to establish the HSAD technology as compatible with development in light industrial areas and within strongly regulated air quality districts. While specific equipment issues continued to reduce the effectiveness of the overall pilot system, in general the integration of equipment systems worked properly with only minor down time. The process control and automation system represented another success in that the plant operation was demonstrated to be reliable. Thus if used in commercial scale systems the process would require only minor operator attention. The development of effective plant operating and safety procedures allowed operators with little or no mechanical, computer, analytical analysis or data logging experience to be trained to be effective at maintaining and operating the plant. This expands the manpower base if needed, for commercial scale system installations while reducing labor costs.

Once issues relating to system heating and agitation were addressed, the anaerobic consortiu (biocatalyst) did reach critical mass and performed very near expectations indicating that even relatively small amounts of starter culture may be used to initiate commercial scale syste (although requiring additional startup time). Unfortunately, because of the mixing problems, one of the project goals, demonstrating the HSAD technology at advanced organic loading rates of $20 \mathrm{gVS} / \mathrm{Ld}$, was not fully met. Instead, the HSAD process was demonstrated at OLRs approaching $15 \mathrm{gVS} / \mathrm{Ld}$ while achieving conversion yields averaging greater than $80 \%$ of that determined in previous studies with smaller scale systems.

A large number of important system design and engineering criteria for large scale HSAD systems were identified and corrected. This will dramatically reduce the perceived level of risk involved in further developing the HSAD technology at commercial scale. 


\section{Potential Future Efforts}

It is important to recognize that the HSAD pilot system currently provides three elements which are critical to the commercialization of this technology including:

- Plant tours and system evaluations by perspective system customers

- Ability to develop HSAD data for alternative organic waste feedstocks

- Production of process effluent as starter culture for commercial systems

The pilot scale HSAD system is especially critical in producing sufficient starter culture to achieve a rapid startup for a commercial system. The longer lag phase experienced in the startup of the pilot system was at least partially due to the relatively small volume of starter culture available. While the use of "filler sludge" filled the void requirement, its use may have also resulted in high free ammonia concentrations which may have at least temporarily inhibited the anaerobic consortium and further extended the startup phase. Initiating a commercial scale plant with a full working volume of starter culture would reduce the startup period to a matter of weeks rather than months.

With some additional equipment modifications, the pilot scale HSAD system can continue to provide research and development capabilities as well as providing effective volumes of starter culture for commercial projects. However, once the first commercial scale HSAD system is operational, it will serve as the source for starter culture for additional commercial projects. At that time the pilot scale HSAD system may then be dispensable or may continue to serve a role in research and development activities.

We currently anticipate the need for operation of the pilot HSAD system for a period of 12 to 18 months, after which a 2-month decommissioning period may follow. A time extension has been requested on all pertinent operating permits for the pilot plant operation. Specific elements of potential future operations (should the necessary funding be acquired) are described in Table 7 . 
Recycling and Energy Recovery Pilot Project

Table 7. Potential Future Pilot Scale HSAD System Efforts

\begin{tabular}{|c|c|l|}
\hline Start & End & \multicolumn{1}{c|}{ Activity } \\
\hline \hline $09 / 98$ & $10 / 98$ & $\begin{array}{l}\text { Assess engineering approaches including cost and timing to provide } \\
\text { for adequate digester drive torque requirements }\end{array}$ \\
\hline $10 / 98$ & $12 / 98$ & Install new equipment to provide reliable digester agitation \\
\hline $12 / 98$ & $12 / 98$ & Reinitiate Pilot Scale HSAD operations \\
\hline $12 / 98$ & $02 / 99$ & Evaluate methods for longer term storage of HSAD starter culture \\
\hline $02 / 99$ & $06 / 99$ & $\begin{array}{l}\text { Process effluent collected as starter culture for commercial scale } \\
\text { system startup }\end{array}$ \\
\hline $06 / 99$ & $12 / 99$ & Additional alternative feedstock testing at pilot scale may be pursued \\
\hline
\end{tabular}

\section{Lessons Learned}

It should be understood that in scaling up any new technology such as the HSAD process, there is likely to be both mechanical and operational problems that are unforseen even with the most thorough planing and preparations. In reviewing the design and operating plans for the HSAD system substantial time and effort was devoted to health and safety issues through formal HAZOPS review. NREL, BRI, and Black \& Veatch all participated in this review which was extensive and ultimately resulted in safe and secure plant operations.

Considerable time was spent by NREL, BRI, Black \& Veatch and Envirex in reviewing the project objectives and the HSAD system design. Substantial information was provided to the project team by NREL researchers on past efforts, process data and general performance requirements. Some equipment specifications were also provided by NREL to the project team to guide the system design, engineering and equipment procurement. In addition, the project team selected recognized experts in equipment design and fabrication to provide critical components for the pilot system. However, critical engineering mistakes were made, especially regarding the HSAD bioreactor agitator drive, which slowed the progress of the project. These engineering mistakes may have been minimized or avoided altogether if proper equipment pretesting was conducted. Regardless of the initial errors in equipment engineering or pretesting, the most substantial issue related to the vendor's unwillingness to satisfactorily correct the problem in the field. Understanding the novel nature of this emerging technology and the critical role played by their piece of equipment, the vendor was unwilling to take ownership of the issue 
and correct it. The project management team was equally unsuccessful at resolving the proble and additional funds were not available for third party corrections to be implemented.

Key lessons learned involve instituting a more thorough engineering and design review and selecting vendors that have produced equivalent types of equipment. Equipment vendors must also be held accountable that equipment meets or exceeds the design performance specificiations in order to safeguard the project goals. Construction and commissioning issues are also key. Selecting the best team to provide unique solutions to construction challenges in the field and thorough testing and validation of all equipment systems prior to commencing startup operations increases the confidence in plant operations and process control while speeding progress toward the operating phase. 


\section{Specific Mechanical and Operational Issues}

It is important to state that many of the issues described below are inherent in pilot scale syste equipment and emerging technologies. Problems associated with short cuts or less than ideal designs and equipment result in operational difficulties that may not be experienced in a full scale system properly designed and managed.

MSW feedstock-

1) MSW Quality/Quantity Issues.

- The project suffered a weakness in the ability to procure a consistent quality and quantity of MSW feedstock from the material recovery facility (MRF). The majority of the problems stemmed from a lack of interest by the MRF staff to perform the sorting function. In general, the MRF operators were interested in "filling the bag" to get the job done rather than selecting the correct materials. Pulling paper and cardboard from the conveyor line was fastest and provided more bulk to fill the bag than food and yard waste. Therefore, we generally received a MRF feedstock which was substantially high in paper and cardboard. Our attempts to re-educate the operators or the MRF supervisor had only short term effects. On some occasions, (and for unknown reasons) the MRF did not produce sufficient amounts of MSW feedstock. This required us to abandon our "just in time" MRF feedstock inventory control, and to maintain at least a one day backup of feedstock. On other occasions, the MRF equipment was not operative and they were unable to produce any feedstock. There was often a lack of communication by the MRF management to informed us before hand of any problems with preparing the feedstock supply.

2) MSW Shredding.

- The Jacobson shredder is equipped with a programmable logic controller (PLC) which serves to prevent injury to the shredder should inappropriate materials be introduced. During initial commissioning of the shredder, the unit was diagnosed as having a proble with the software logic contained in the PLC. It was determined that the PLC was shipped without a battery backup to maintain the volatile memory. The equipment vendor made a site visit to reinstall the software and a backup battery.

- A hydraulic oil leak on the feeder ram was traced to a hairline crack in the hydraulic oil filter. The filter was replaced and the reservoir refilled with oil.

- The shredder was equipped with 4 belts on the drive which over the first 6-months of operation, stretched to the point of slipping. Without proper maintenance, the belts burned out. The belts were subsequently replaced and routine maintenance performed to check the belt tension every 2-4 weeks. 
3) MSW Transport.

- $\quad$ MSW bags (super sacks) with full bottom discharge were used to contain the sorted and shredded MSW. These bags had a limited life span as the discharge straps would shred, cut or otherwise fail, making the bags useless.

- $\quad$ MSW bags needed to be dried after use, retied and transported back to the MRF. This required a large inventory of bags to be available.

- The double axel trailer while sufficient for the weight of material to be transported (up to $5000 \mathrm{lbs}$ ), had dimensions which would only allow 3 to 4 bags to be safely placed on it for transport. Since routinely, the plant required 6-8 bags per day, we were therefore required to make multiple trips to the MRF to get feed every day.

- Bungee cords were used to tie down the flaps on the MSW bags while on the trailer and during transport to the pilot plant. These bungee cords were found to be a safety concern for the operators in attaching and removing them.

4) Food Sludge Receipt.

- The tanker truck used to deliver the food sludge feedstock represented an odor nuisance anytime it entered the pilot plant grounds. A garden sprayer filled with an industrial odor neutralizer was used to spray the tanker truck in order to minimize its impact on our neighbors.

- Delivery of food waste feedstock was occasionally interrupted by either a slow-down at the food processing facility or a conflict in schedule with the transport company.

5) Food Sludge Storage.

- Piping (2-inch) was considerably undersized resulting in problems with the ability of the double diaphragm pump to move thick sludge from the transport truck to the plant's storage tank. The piping also contained multiple $90^{\circ}$ elbows which further restricted the flow of food sludge. The piping was installed without sufficient pipe unions making disassembly for cleaning and repair difficult.

- In some cases, plastic wastes including coffee stirrers and plastic film contaminated the food sludge feedstock resulting in a plug forming in the recirculation line and at the pump. A basket strainer was installed to remove this plastic waste during food sludge transfer to the plant's storage tank. The small size of the strainer required multiple cleanings during transfer increasing the time and complexity for transferring food sludge and increasing the potential for odor emissions and neighbor complaints.

- An air sparger was installed in the food sludge tank (T-201) during the final construction phase. The rubber air hose was not secured to the inner tank wall and was sheared by the tank's vertical agitator blade. The sparger ring and attached hose was "fished out" of the tank and not reinstalled.

- The food sludge tank was equipped with a vertical mixer (Brawn, R-201). The agitator blades on the mixer shaft were substantially small as compared to the diameter of the tank and this coupled with a high shaft speed and thick sludge consistency resulted in a small 
zone of mixing. In addition, the mixer was not equipped with sealed bearings at the shaft's penetration into the tank which resulted in odors escaping from the tank when the mixer was operated.

6) Food Sludge Transfer to the Feedstock Mix Tank.

- Small piping and multiple elbows were also used here which restricted the flow. Some of the elbows were replaced with multiple $45^{\circ}$ angles.

- The solenoid-controlled ball valves were not installed with manual operators to over-ride automatic operation should the control system be inoperative for any reason. Manual operators were added to these valves.

7) MSW Feedstock Loading to Mix tank.

- Daily loading of MSW in super sacks to the mix tank required the use of the forklift and skilled operators. On more than one occasion, the forklift caused damage to the ceiling insulation and a nearby hanging light fixture.

8) Feedstock Mix Tank Operation.

- The lid to the Feedstock Mix tank did not seal correctly allowing odors to escape into the plant. A foam insulation tape was applied to create a good seal. This foam tape required replacement approximately every month.

- There was no provision for the addition of water to the feedstock mixing tank to dilute the feedstock. A hose connection to the domestic water was installed for manual addition of water to the mix tank.

- $\quad$ The ribbon blender agitation design of the feedstock mix tank was not a good match for all of the feedstock materials we used. While the design provided a well mixed material in several minutes, ribbon blender type agitators are intended for use with "friable" materials. This is because the ribbon actually pushes solids down the length of the tank and compresses it against the wall until it is "squeezed" out and falls into the path of the opposite ribbon. Generally where our feedstock contained a larger amount of food or yard waste or if we added a significant amount of food processing sludge, the mixture was amenable to this type of mixing. However, during at least one period in which only shredded paper was used as feedstock, the moistened paper would clump into a nonfriable mass which caused substantial torque and rotational problems for the ribbon mixing system. On one or more occasions in which only paper was mixed, it is believed that damage occurred to the ribbon agitator packing glands and drive gear box.

- The ribbon agitator design imparted substantial heat to the feedstock as a result of frictional forces during continuous mixing. The agitator speed could have been slowed considerably during continuous mixing to reduce both heat input and power requirements.

- The mix tank agitator motors were installed with incorrectly sized fuse links at the motor control center (MCC). This resulted in the burnout of two $10 \mathrm{hp}$ electric motors during a 
period of high torque. The correct size fuse links were installed to prevent damage to the electric motors.

- The mix tank agitator drives were equipped with Sumitomo gear boxes to reduce the speed of the electric drive motors. One of these gear motors experienced high internal resistance loads and failed. Following removal and inspection of the failed gear box it was determined that insufficient lubrication may have contributed to the failure although damage due to mixing paper only feedstock was most likely the cause. Relative to the lubrication issue, Sumitomo, the manufacturer, indicated that the specific gear boxes which were installed did not need lubrication service because of high viscosity grease that was used.

- The mix tank drive system utilized a chain drive from the gear box to the agitator shaft. The drive chain consistently "slapped" the chain guard housing (although tensioned as recommended) creating substantial noise and potentially destroying the chain and guard over time. Chain tensioners were installed on both drives which eliminated the problem

- The mix tank auger and feed screw motors were specified with variable frequency controllers (VFC) which allowed the delivery of feed to the digester to be controlled by the computer system. These VFC systems are susceptible to grounding and power feedback if not properly wired. However, the same conduit was used for power and control wiring which resulted in multiple problems with electrical faults and improper operation.

- While the VFC's were specified and equipped with the ability to operate their respective motors (electrically) in the reverse direction, they were not properly wired for this operation.

- A safety latch on the feedstock mix tank lid did not consistently and properly engage when the lid was opened.

- The mix tank packing glands were fitted with brass couplers. The coupler set screws were not adequate to keep the couplers in place.

- The ribbon agitator packing glands as well as the mixer auger gland leaked liquid from the mix tank. This condition generally could not be adequately controlled by tightening the packing gland collar. This lead to smelly squezate which produced odor and required constant cleaning to maintain an orderly appearance.

- The feedstock mix tank load cells registered a significant difference in weight measurement due to vibration when the mix tank agitators were running.

9) Mix Tank to Digester Feed System.

- A two-screw feed system was designed to allow differential weights for the mix tank and digester to be maintained by virtue of a rubber isolation boot. However, if for some reason the digester feed screw stopped moving material, feed would back up in the rubber boot area between the screws and then a plug would form in the mix tank screw stopping operation. This required an extensive period of time and effort to clean out the intermediate boot area, unpack the mix tank screw, and restart the digester screw to feed 
material. The general cause of this problem was liquid flooding the lower, digester feed screw creating a slurry. Because of the incline of the feed screw to the digester, the screw was unable to move a slurry and additional feed would begin to form a plug. This excess liquid was a result of liquid in the digester which would flow back down the screw, or excessively wet feed in the mix tank which would "weep" down the screw and through the boot to the lower screw. This problem could be solved by changing the elevation of the digester feed screw to angle in a downward direction toward the digester. In this way, excess liquid would drain toward the digester and away from the feed boot area.

- The thermocouple intended to measure the temperature of the feedstock entering the digester was welded to the outside of the feed screw piping. The thermocouple therefore only sensed the temperature of the pipe and we were unable to get an accurate reading of the temperature of the feed entering the digester system.

- The heating loop which supplied heat to the feed screw jacket was not designed or installed with a separate temperature control. We were therefore unable to increase the temperature of the feed screw jacket without affecting the temperature of the main digester heating system. This reduced our ability to effectively preheat the feed prior to entering the digester.

- Automatic (solenoid) valves used to control heating loop flow were not specified with manual control (operators) and could not be operated if the computer control system was inoperative for any reason. These valves were removed and new solenoid valves with manual operators were installed.

10) HSAD Digester

Agitator System

- From the beginning, the agitator drive system was ineffective at mixing the digester contents. Early studies at NREL indicated a need for approximately 3-4 hp per 1000 cubic feet of sludge at $25 \%$ to $30 \%$ total solids. Using this information, the pilot digester having a total volume of 40,000 liters (1,413 cuft) and a working volume of 32,000 liters (1,130 cuft) would require somewhere between 3.39 to $4.52 \mathrm{hp}$ for the drive system. Instead the vendor used a $1 \mathrm{hp}$ hydraulic motor attached to a severely undersized gearbox (Hub City). In fact, in order to accommodate such a small gearbox, the end of the agitator shaft was "turned down" from approximately 3.25 -inches in diameter to 2.125 -inches. This effectively reduced the overall torque capacity of the agitator shaft thereby limiting the drive system which could be used. It is important to note that the vendor (Envirex) was chosen as a recognized expert in this field and provided assurances that their equipment would perform as per specified. Later, they refused to correct the problem without additional costs and their resolution only partially improved the equipment performance.

To reduce the required level of torque, sludge was removed from the digester and approximately $50 \%$ of the agitator tines were removed. The replacement gearbox (Nord) was capable of a maximum torque of 4,000 foot pounds (the maximum for the $1 \mathrm{hp}$ 
hydraulic motor). The capabilities of the replacement gearbox made the digester agitation system only marginally useful as we were required to add water to the digester contents to "thin the mix" and thereby maintain low torque loads on the agitator. Dilution of the digester contents had a negative effect on the process rates and yields as well as reducing the quality of the compost. An equivalent volume of dilution water to that of the daily feed was added to the digester essentially diluting the solids level from $35 \%$ to $17.5 \%$. On several occasions, the agitator torque load increased beyond the maximum limit of the drive system and the agitator stopped.

- The location of the agitator drive system was also questioned. The agitator drive system was installed by the vendor at the far end of the HSAD system. Since the greatest torque load on the agitator is at the front end where the high solids feedstock is introduced, the drive should have been installed at the front end of the digester to reduce the twisting torque along the length of the agitator shaft.

- There was no provision for the addition of dilution water to the front end of the digester. A hose connection to the hot water supply was installed on the front antifoam port on the top of the digester. An automatic timer-type control valve was used to provide consistent water addition.

- Optical encoder type speed sensors were installed to monitor the motor rpm on the digester agitator and moyno pump. These optical encoders were unnecessarily complex, costly and were relatively unreliable. The speed sensor on the agitator required factory repair after 8-months of use while the speed sensor on the moyno pump never actually worked. A low cost magnetic reed switch type sensor would have been both durable and inexpensive.

11) Digester Gas Collection

- The digester biogas pressure sensor was specified with a range of $0-25$ psi. Since normal digester pressures averaged 0.3 to $0.5 \mathrm{psi}$, the accuracy of this sensor was marginal. In addition, the pressure sensor was installed on a blind section of pipe that lead to a pressure relief valve outside of the building. This pipe section had the propensity to fill with condensed water vapor further reducing the accuracy of the pressure sensor.

- Low-pressure biogas safety relief valves were specified at a pressure setting which was too close to the digester system's operating pressure. This low setting allowed the valves under certain environmental conditions to "chatter" and release biogas. This biogas release reduced our product measurements as well as creating a potential inflammability hazard. Additional weights were added to 4 different safety relief valves to achieve the correct relief pressure range.

- The Walker biogas surge tank used a strip gauge to monitor the internal gas volume. The strip mechanism would transiently "hang up" giving erroneous readings. Simply bumping the gauge would reset the strip. This problem became less significant after lubrication oil was added to the meter housing, but was never completely corrected. 
- The biogas flow meter was specified to monitor gas flow over a rather limited range of 20 to 566 liters per minute. During startup when biogas production was low and during maximum loadings, the gas meter was unusable.

- Biogas line manometers (3) were installed in an outdoor location without protection from the rain. An aluminum cover was installed over each manometer to eliminate intrusion of rainwater.

12) Biogas Cogeneration System

- The Stewart Stevenson Cogen was specified for 60\% methane content biogas and the unit would not perform to its rated capacity on biogas with a methane content less than $59 \%$. We were never given an adequate explanation as to why the manufacturer did not design the equipment to perform as rated with fuel gas which may vary by as little as $\pm 10 \%$. Field service adjustments to increase the fuel pipe size and carburetor configuration were ineffective at eliminating this problem.

- While the cogen was wired to start automatically when the biogas surge tank was full, for various reasons it would only be able to accomplish this for a short period of time. Blown fuses, overspeed faults and other unexplained maladies were always determined by the service people. Finally, the unreliable nature of the equipment was attributed to the cold climate of Southern California in which the field service technician recommended an engine heater for reliable starting. The engine heater was never purchased.

- The cogen was specified without a catalytic converter on the exhaust. Without a catalytic converter, environmental emissions from combustion of the biogas were considerably greater than predicted as determined during emissions analysis by an outside testing company as part of our Air Quality Permit requirements.

- The cogen heat exchanger was specified with a maximum temperature limit of $160^{\circ} \mathrm{F}$ rather than $190^{\circ} \mathrm{F}$.

13) Biogas Flare

- The biogas control valve was determined to leak fuel gas from "casting cracks" in its aluminum housing. This valve was replaced by the manufacturer. The replacement valve was received with a defective thermal fuse which was also replaced by the manufacturer. The replacement valve was subsequently determined to have a faulty "seat" in which at low pressure (i.e., when the biogas surge tank was empty and the line pressure minimal), the valve would not fully close. The valve could not therefore be used in an automated mode as it was designed. The manufacturer was exceedingly slow to determine the method for rectifying this problem and finally decided to replace the entire valve for a second time. The replacement valve was received on May $15^{\text {th }}$, the very day plant operations were suspended.

- The electronic ignitor for the flare would fail to spark when the system was wet for some time or when the control box became very hot. The problem was determined to be an 
improperly specified relay. The problem was remedied by the installation of a new, correctly sized relay.

\section{4) Effluent Transfer}

- On numerous occasions, the moyno progressing cavity solids pump became jammed with small sticks and other debris. It was determined that the pump had been specified with the smallest annulus (size 12) and was only able to pass particles less than about $3 / 4$ inches in diameter (although this was a 4-inch pump). The same pump could have been specified with a size 32 rotor stator combination which is capable of passing particles greater than twice that size.

- The internal design of the MicroMotion effluent sensor was a reduced and divided pipe which jammed with particulate matter requiring its removal from the system.

- The effluent line was designed without sufficient tees to allow the moyno pump to transfer sludge to different parts of the HSAD system. A tee was added very close to the initial discharge of the moyno pump.

- The In-Line static mixer (Komax), used to blend injected water with the effluent sludge, lost the majority of its internal mixing flights during an 8-month period of use. This may be attributed to the manufacturers design of glueing the flights to the inside of the pipe.

15) Effluent Tank

- The effluent tank was determined to be too small in capacity for effective use. An empty tanker truck can accommodate approximately 5000 to 6000 gallons of effluent sludge. The effluent tank had a maximum capacity of 3,500 gallons which required increased trips per week to empty the tank and only a partial fill of the tanker truck which was wasteful.

- The effluent tank discharge was not designed with a grit chamber to remove dense and abrasive materials like glass, metal and rocks from recirculating through the pump.

- The effluent tank was not specified with an internal mixer and as a result the sludge would routinely form a thick foam layer at the top of the tank. Recirculating the tank contents using the effluent tank pump was only partially effective at breaking up this layer.

- The effluent tank pump was initially installed as a 3-inch pump which was incorrectly sized for the 4-inch piping. This pump plugged on a number of occasions and was replaced with a 4-inch pump.

- The effluent tank pump was the wrong design for this application as debris in the effluent including glass, metal shards, and hard plastic was abrasive to the rubber diaphragms and flap valves ultimately destroying the pump. A trash pump or gear pump may be a better choice for this application.

- The effluent tank overhead discharge line for filling the effluent tanker truck was designed with too many $90^{\circ}$ elbows for the type of pump used (i.e., low pressure, high volume).

- The effluent tank line automatic (solenoid) ball valves were installed without manual operators. 
- A dilution water line on the effluent recirculation line was equipped with a manual ball valve. On more than one occasion this valve was left on and filled the effluent tank unnecessarily. A self-closing water control value would prevent this problem.

- The effluent tank sample port piping was too small and often clogged during use.

16) Utility Systems

Hydraulic Power Unit

- The hydraulic power unit was not plumbed correctly for the 2-hydraulic motor application. This required some reworking in the field.

- The use of a single hydraulic power unit to provide power to 2-hydraulic motors created problems with the operation of one motor when the other one shut down the system (such as during over pressure situations).

- A faulty shuttle valve was removed and was a part of a complex system to allow the moyno pump motor to run in reverse. The design of the moyno pump does not allow it to be operated in reverse.

- The electronic hydraulic flow control valve which operated the moyno pump motor was a continuous source of leaks and problems.

Air Compressor

- The air compressor developed problems in restarting which were traced to blown fuses on one occasion and an improper pressure switch setting on another occasion.

- At one point, the majority of the compressor oil was blown out of the compressor through the dipstick port. As there was no apparent reason for this problem, the oil was replaced and this problem did not repeat itself.

HVAC

- One of the three exhaust system starters became defective and was replaced.

17) Data Acquisition and Control System (DACS)

- Initial problems with grounding and shielding of process monitoring and control wiring leading to faulty readings and process control errors were corrected.

- The ArcNet bridge which was responsible for sending information from the Mystic PLC to the Gensym G2 control system would occasionally send fault messages.

- Initially the Gensym G2 computer control system was configured with insufficient security protection allowing operators to interrupt system operation.

- The Gensym G2 server computer was installed with insufficient hard drive memory capacity (2 GB RAM).

- The Gensym G2 server computer was installed without a reliable data archiving (backup) system.

- Data retrieval as hard copy was not simplified. 
18) Laboratory

- Some laboratory instruments were specified with membrane-type push button controls which were destroyed by the operators. Instruments with dial controls were more durable under use.

19) System Operations

- No floor drains were available in the plant for wash down of process equipment.

- No janitors facilities for mop and cleaning supplies were available requiring the operators to utilize the outside lot for washing buckets and pails and other large items.

- No showers or changing facilities were available for the operators. 


\section{Pilot Scale Digester Biogas Production}

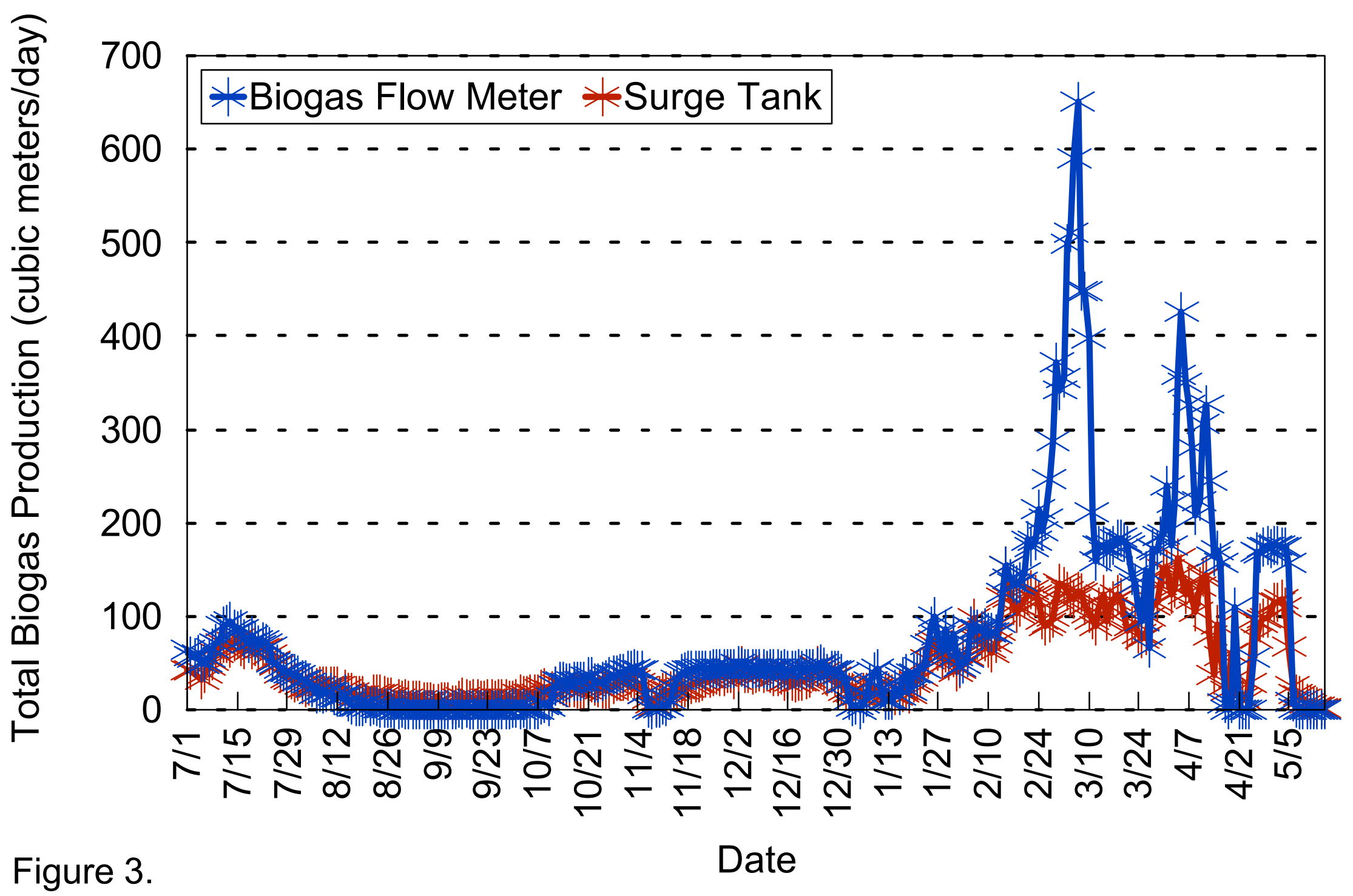




\section{Pilot Scale Digester Biogas Methane Content}

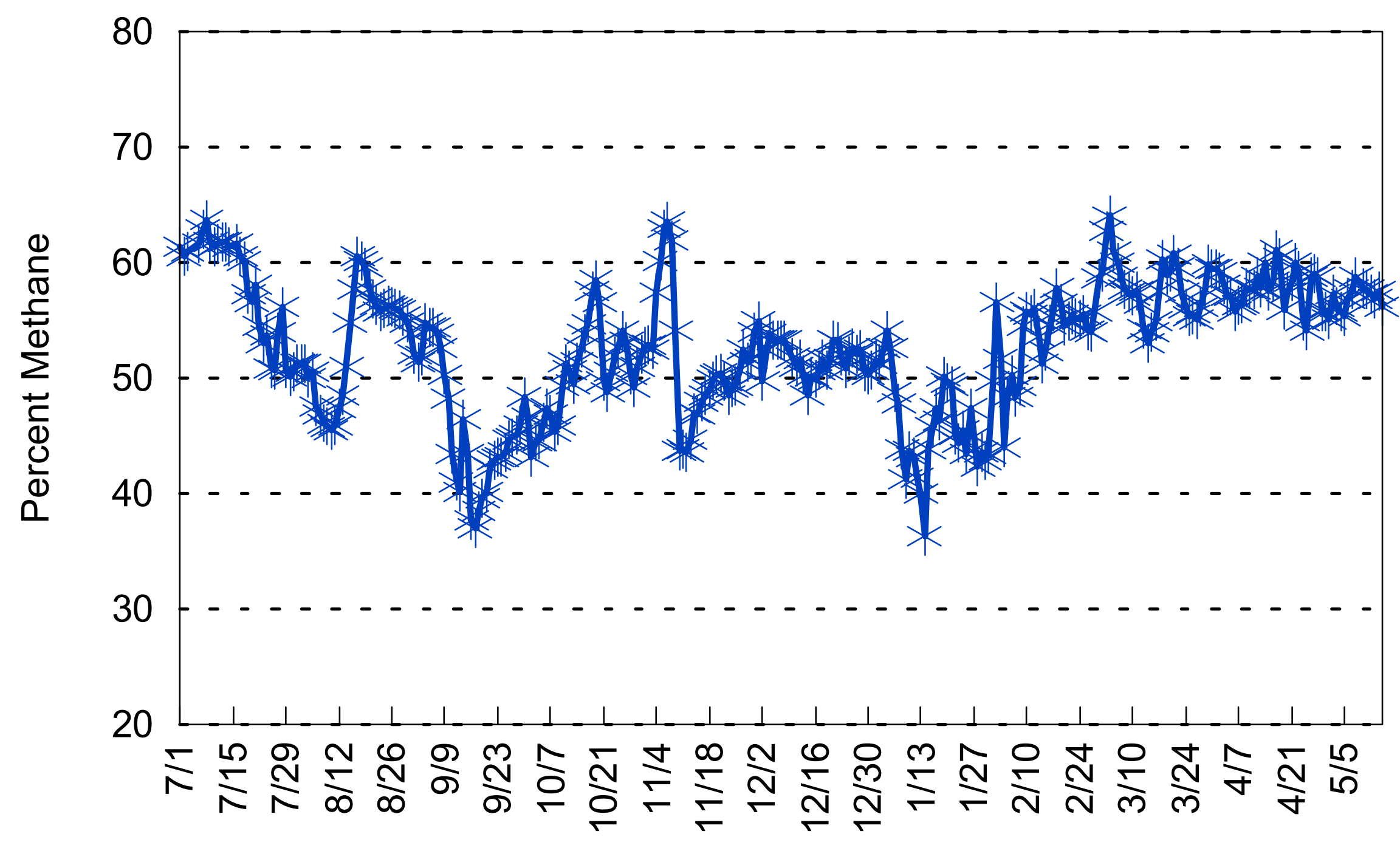

Figure 4.

Date 


\section{Pilot HSAD System Performance}

Comparison of OLR with \% Conversion

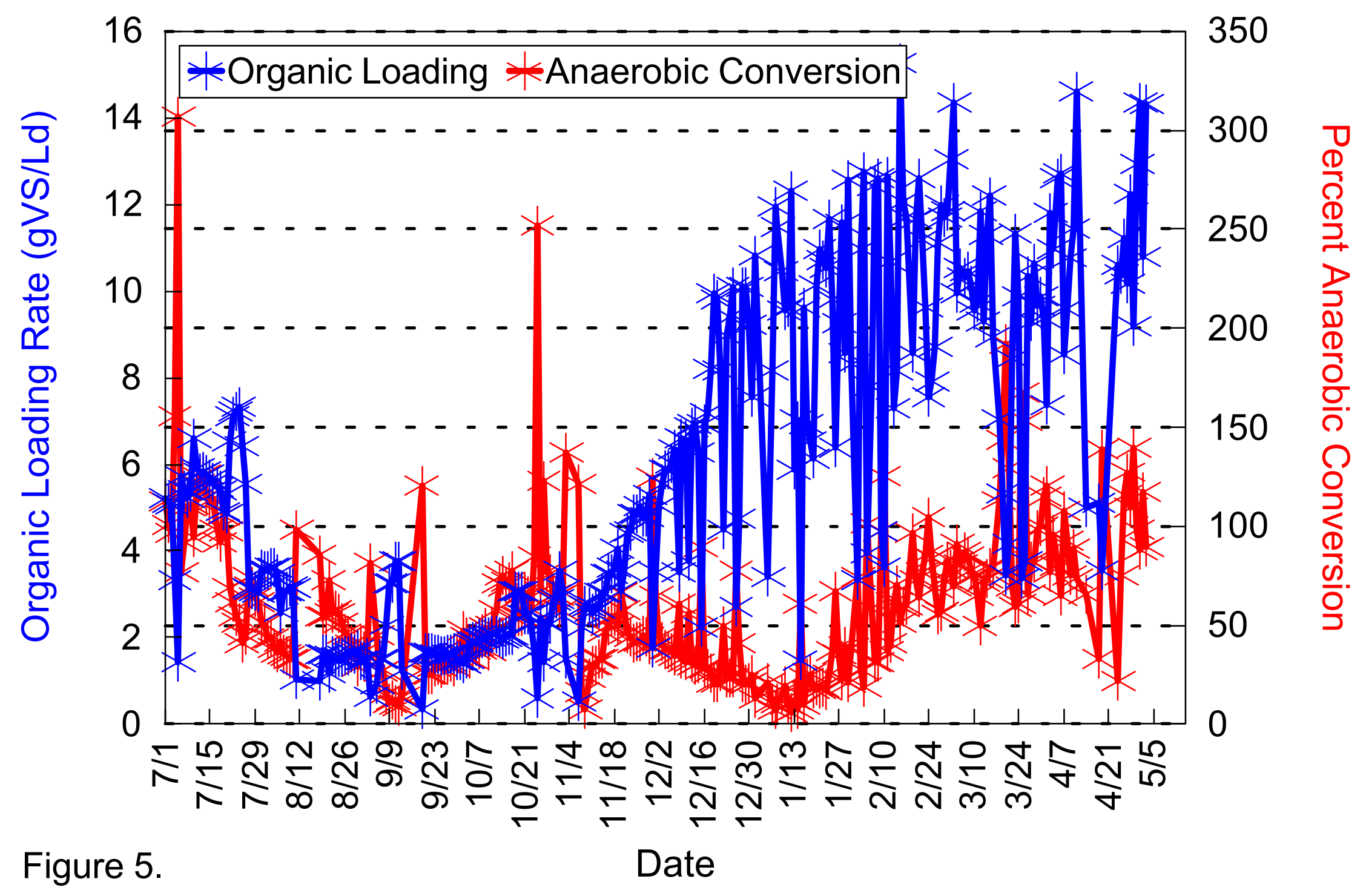




\section{Pilot Scale HSAD Effluent Total Solids}

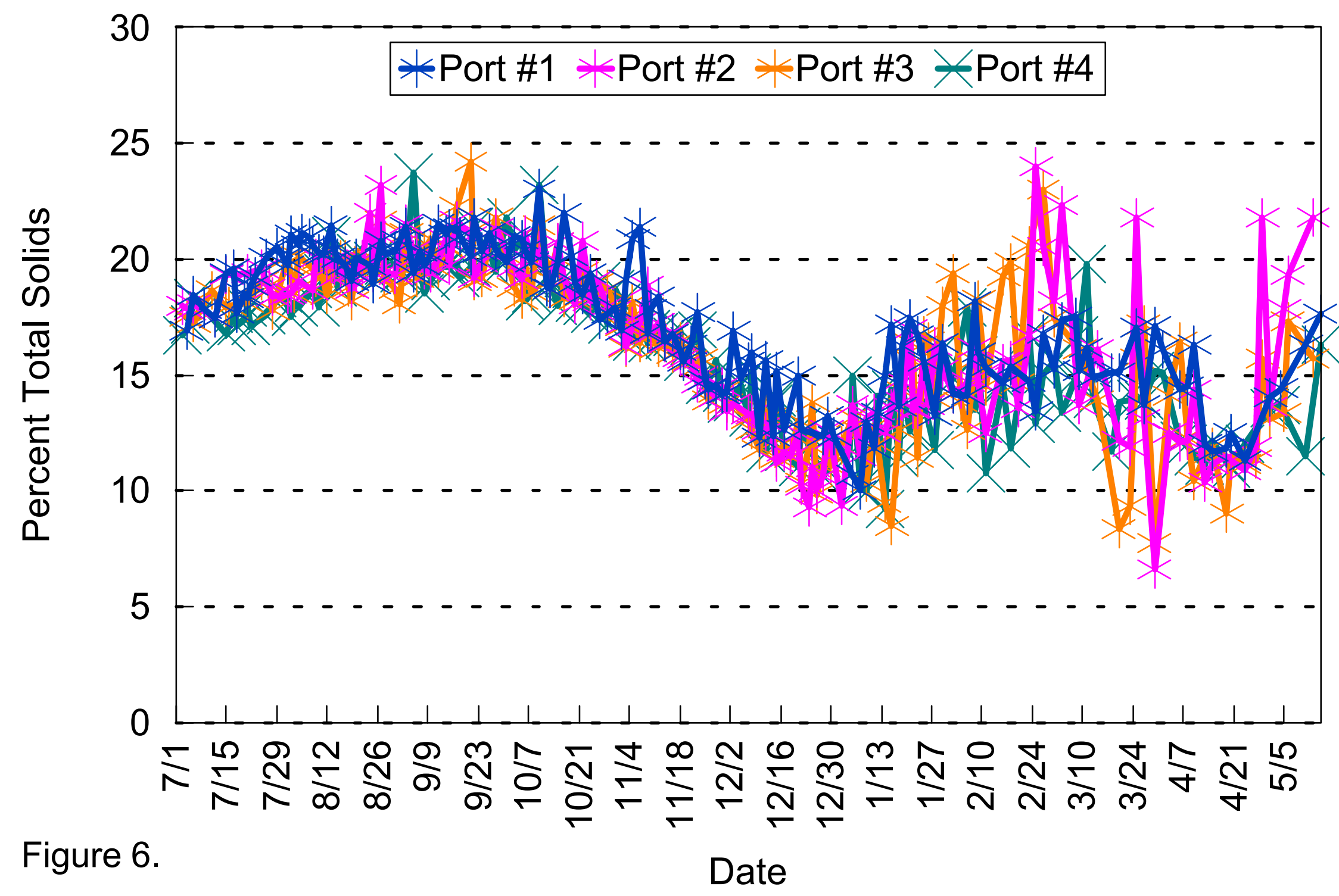




\section{Pilot Scale HSAD Effluent Volatile Solids}

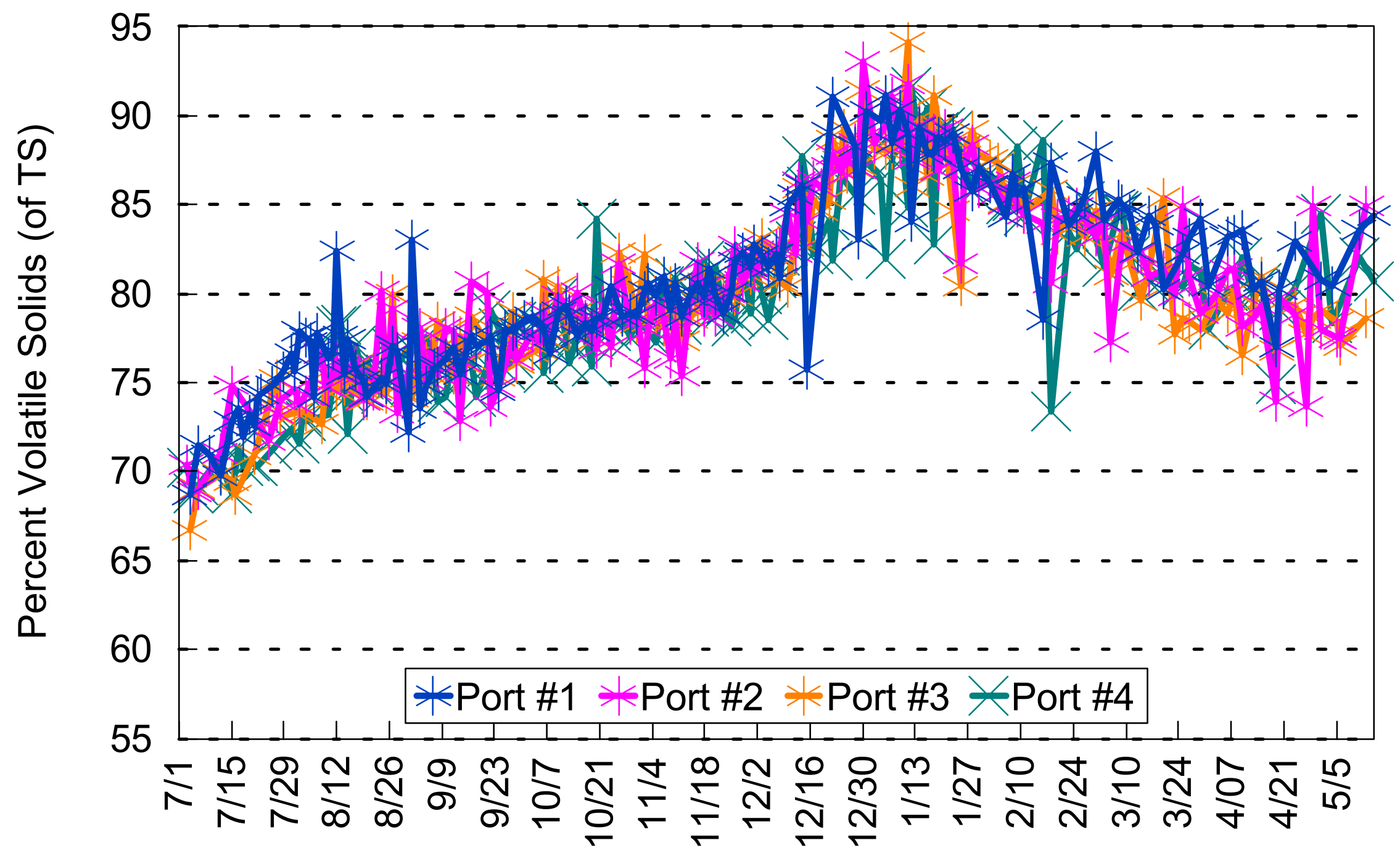

Figure 7. Date 


\section{Pilot Scale HSAD Effluent $\mathrm{pH}$}

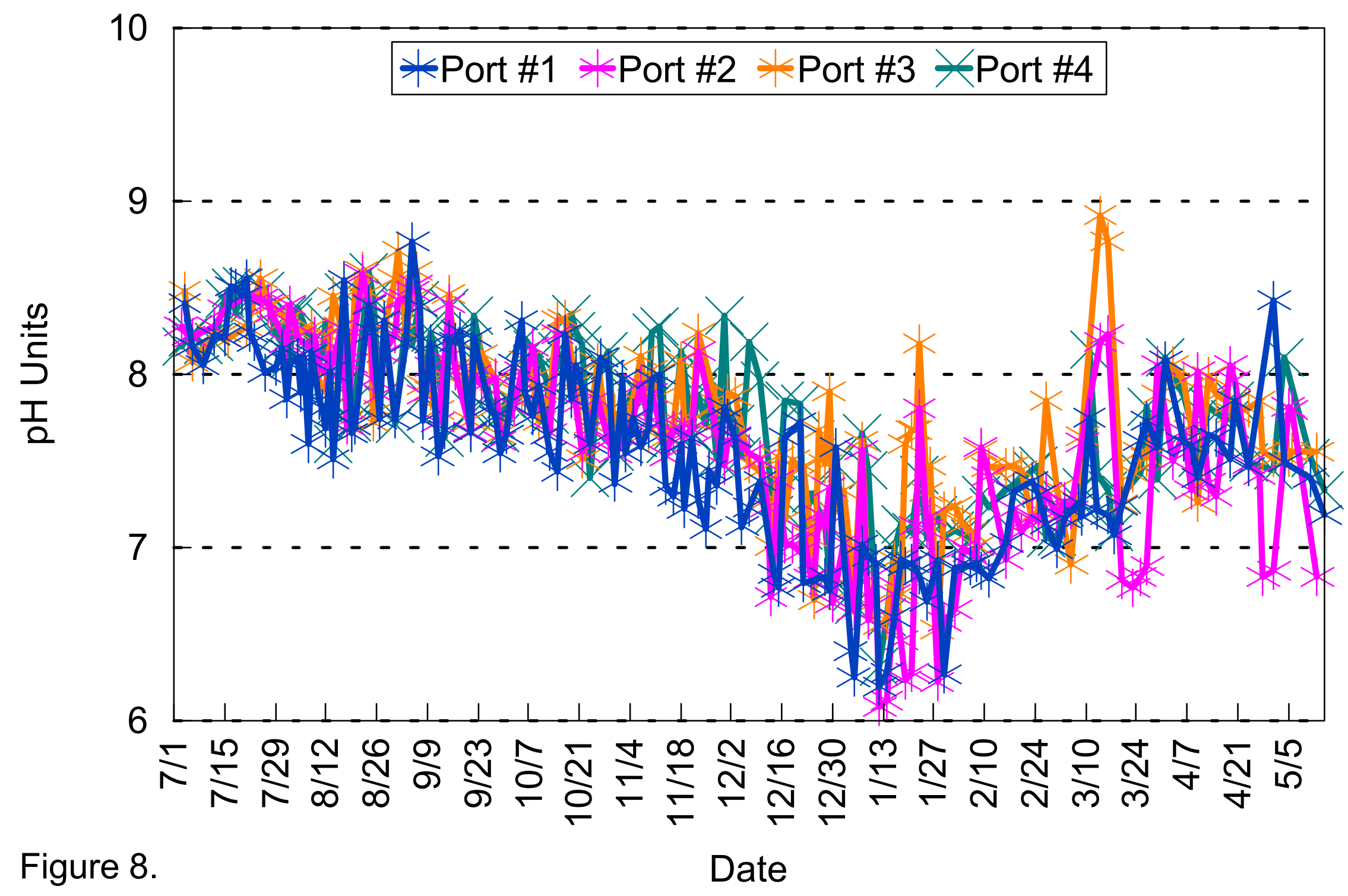




\section{Pilot Scale HSAD Effluent Chemical Oxygen Demand (COD)}

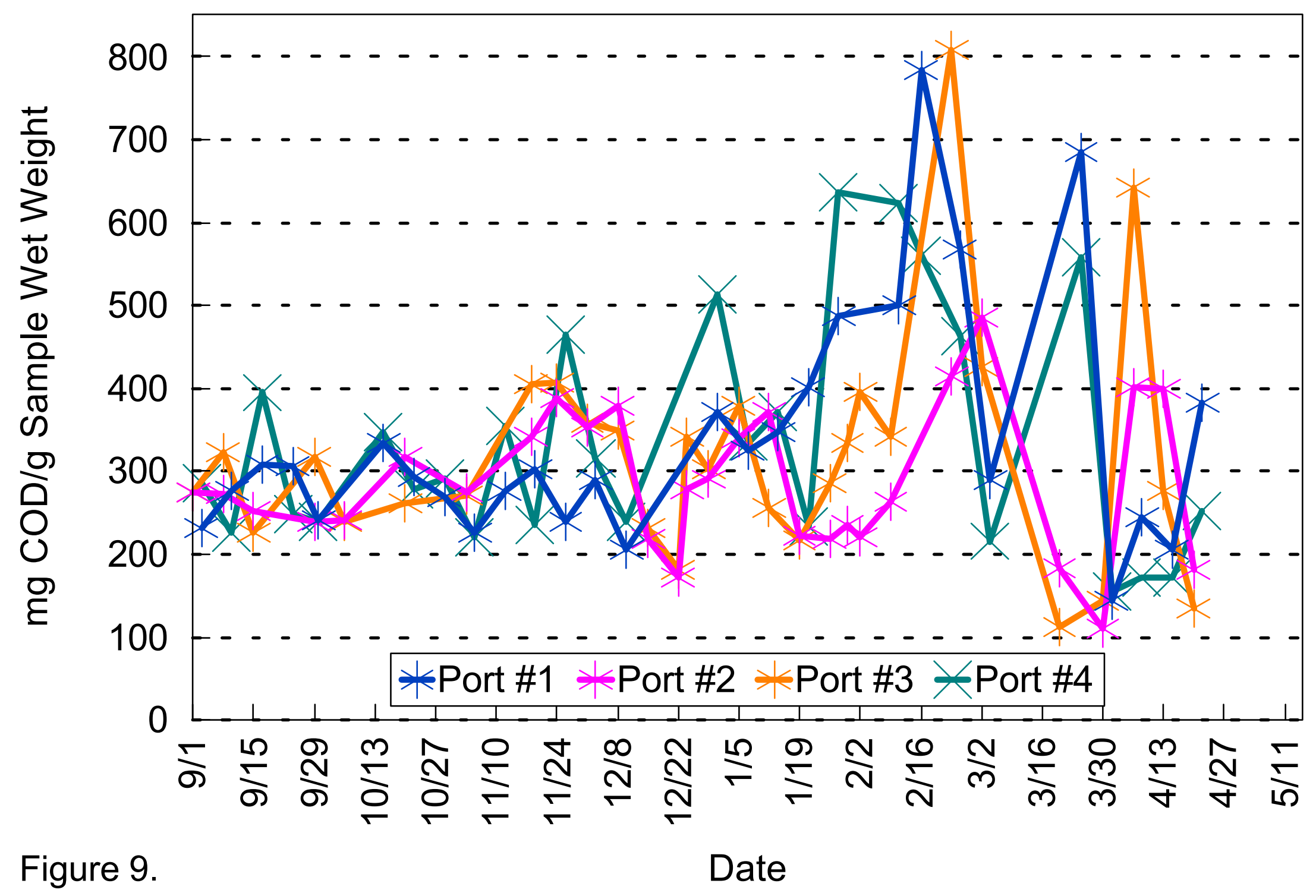




\section{Pilot Scale HSAD Effluent}

Sludge Free Ammonia Concentration

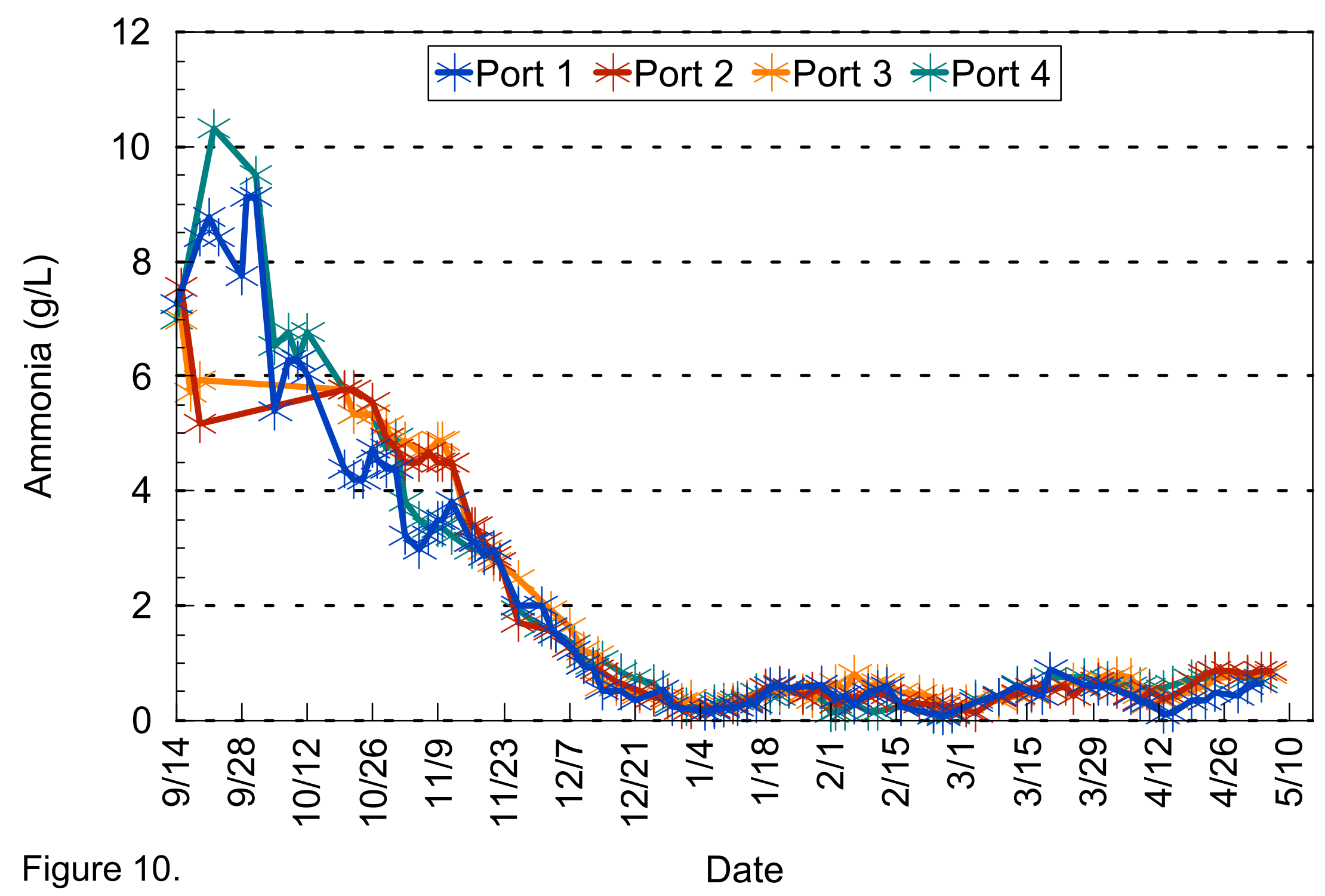




\section{Effluent Tank, T-501}

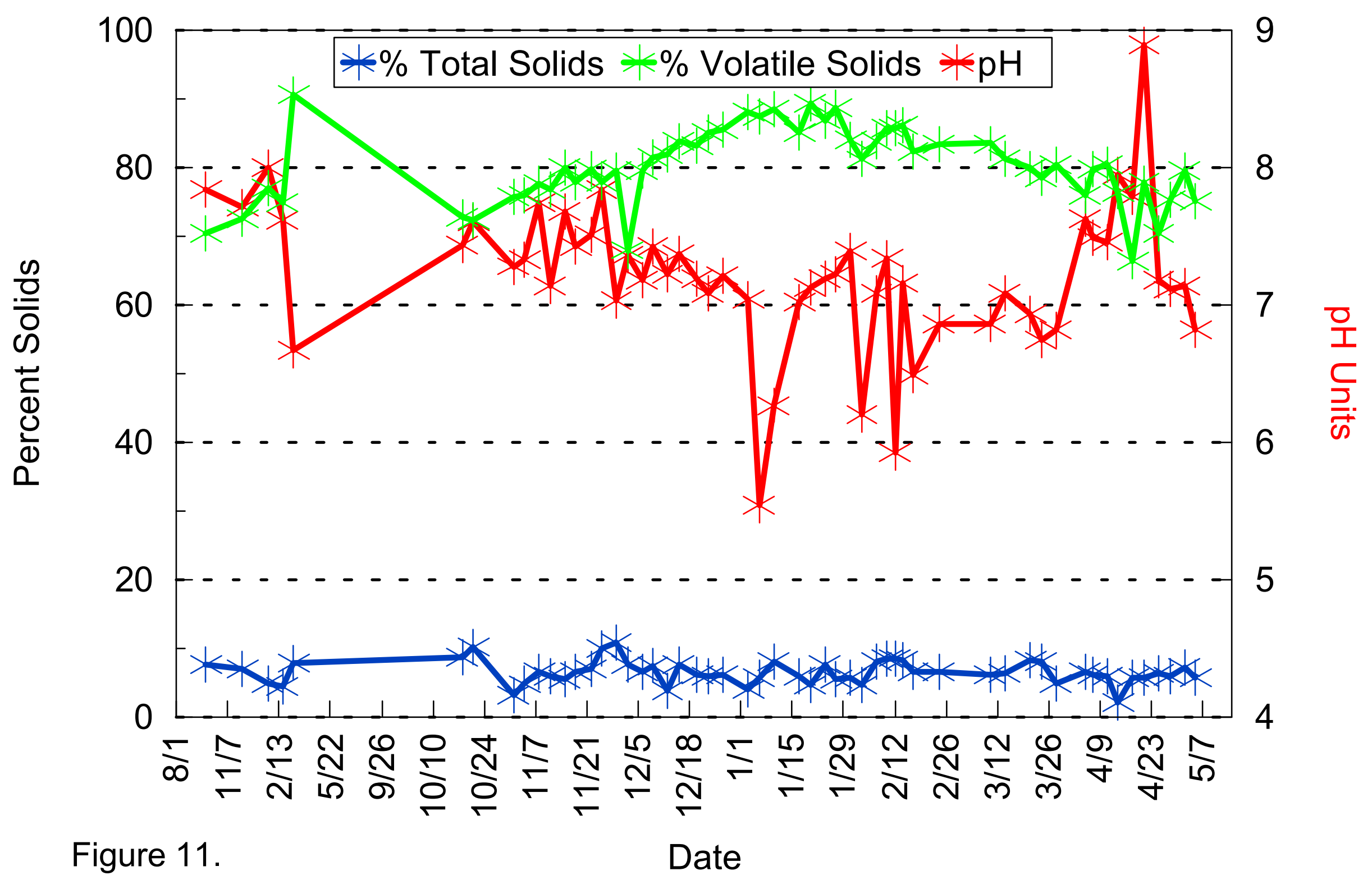




\section{MRF Feedstock}

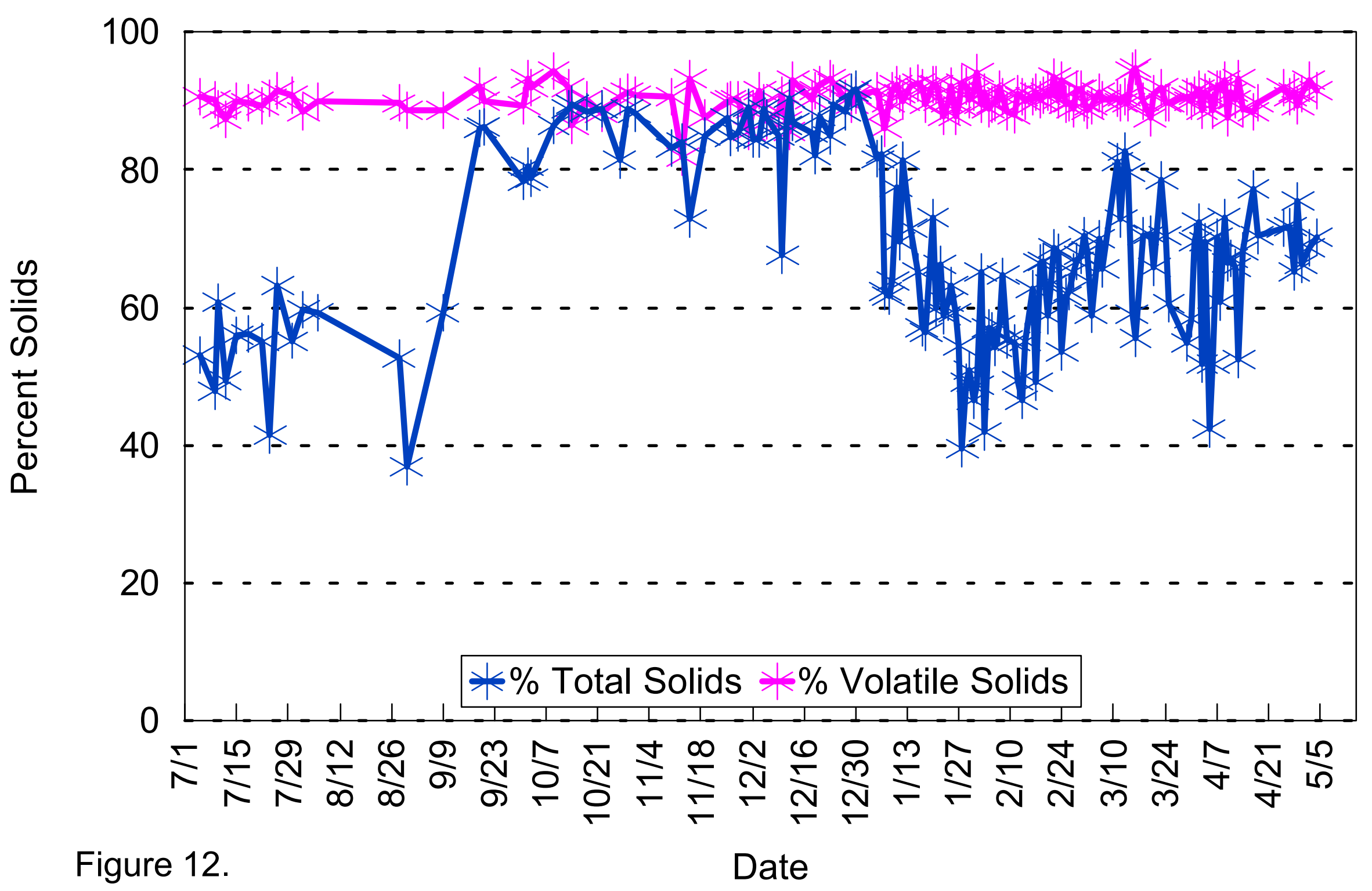




\section{DAF Sludge Feedstock}

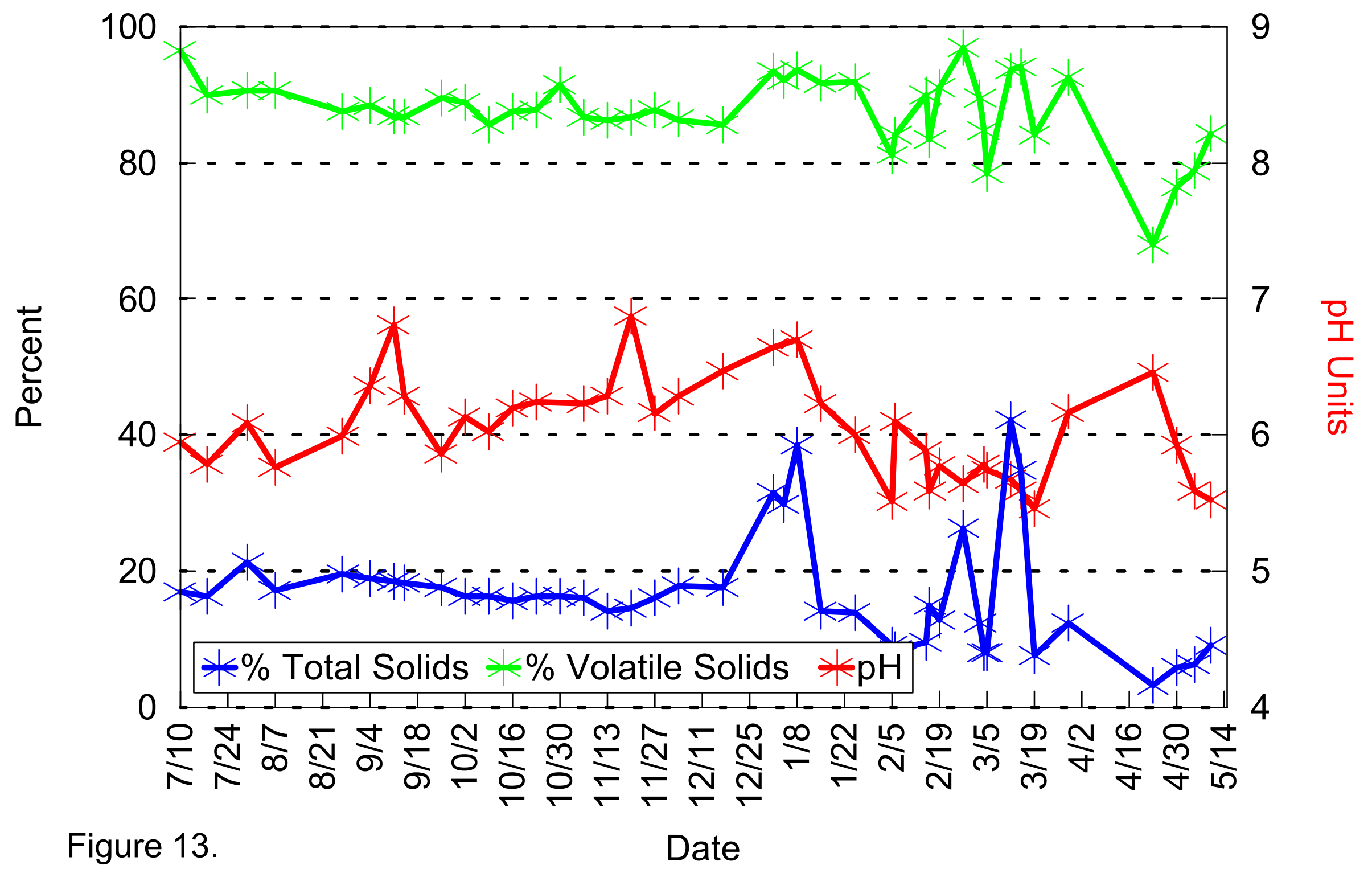




\section{Mix Tank Feedstock}

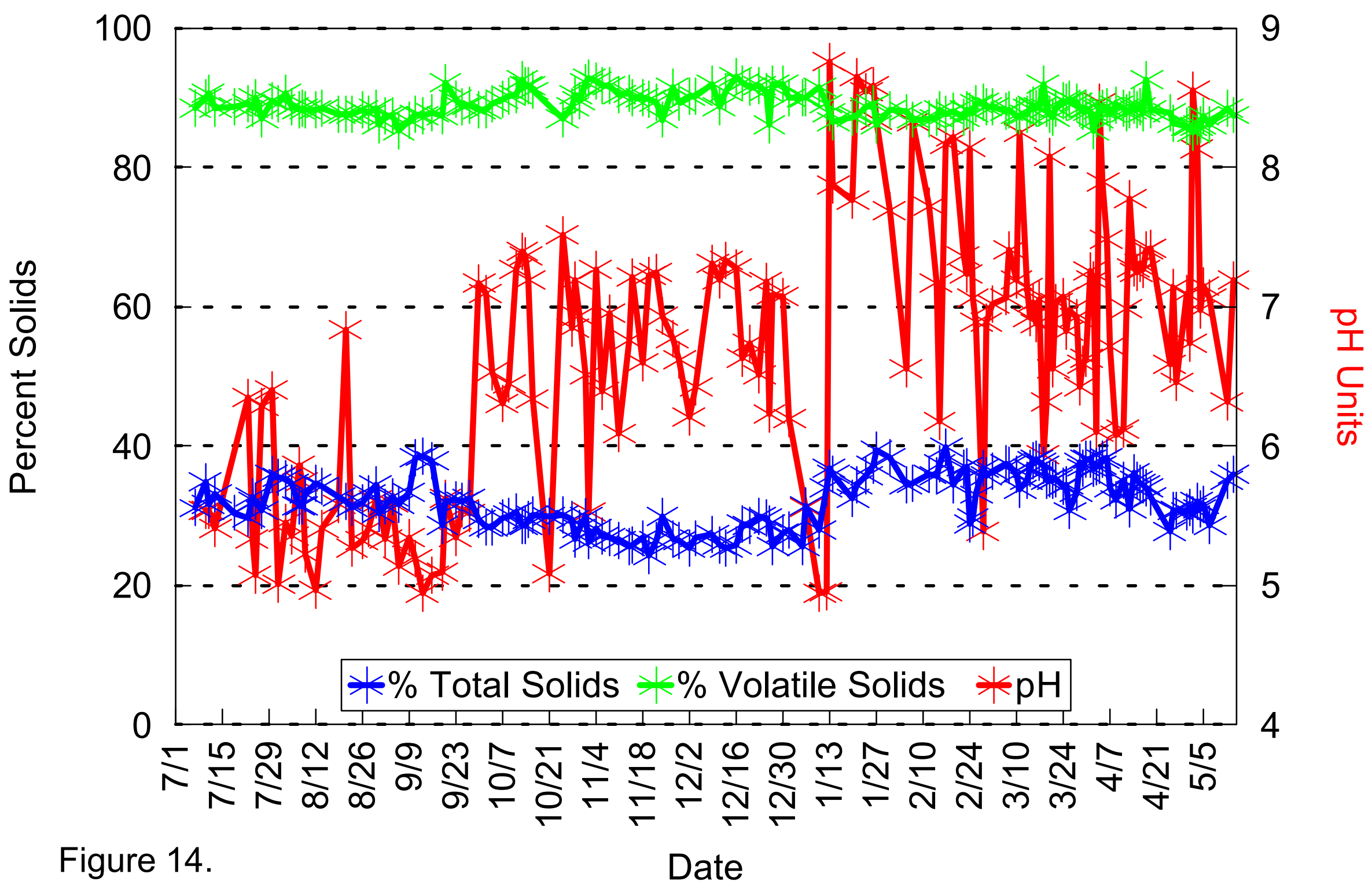




\section{Mix Tank Feedstock Chemical Oxygen Demand (COD)}

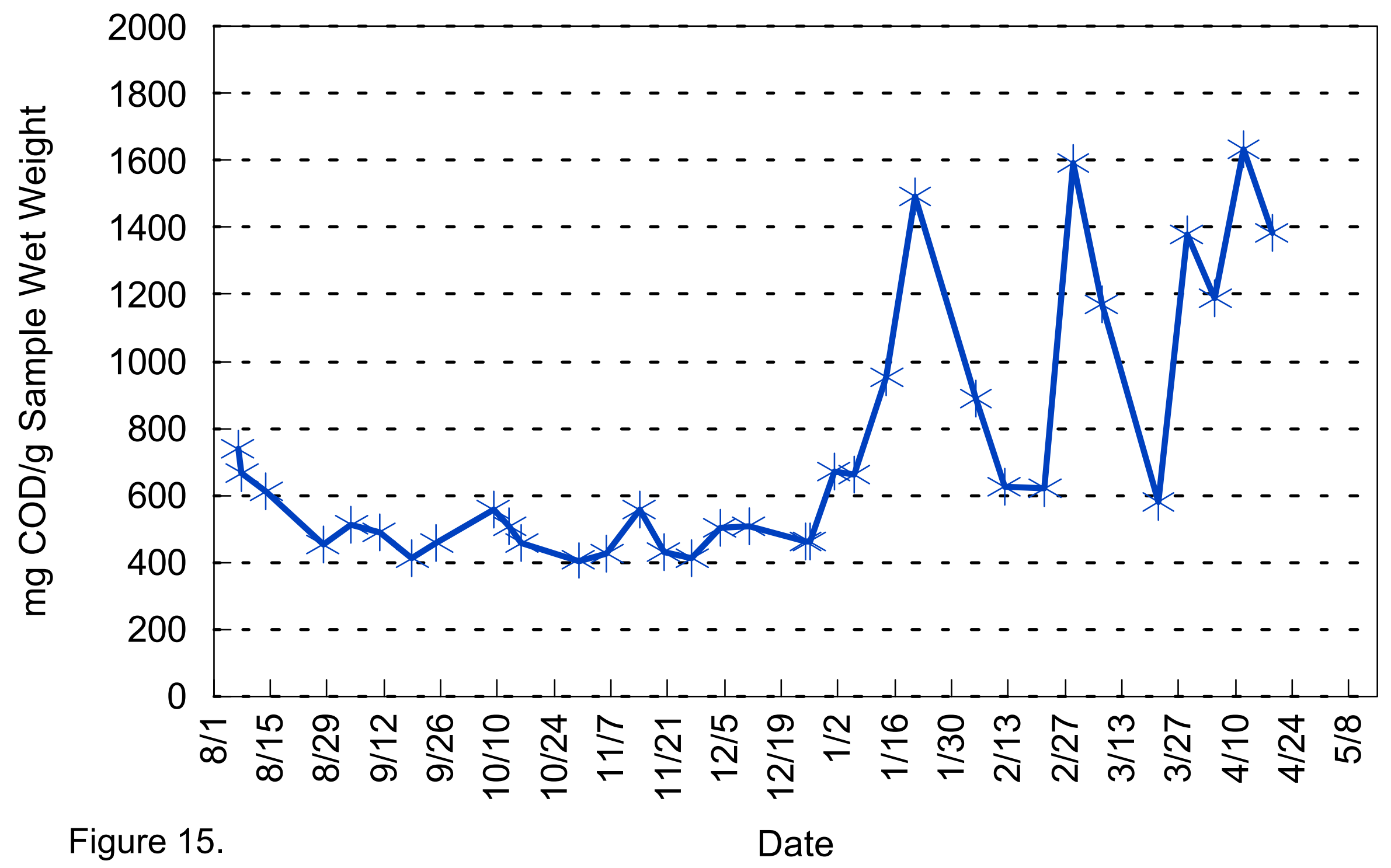




\section{Mix Tank Feedstock}

Combined Feedstock Free Ammonia Concentration

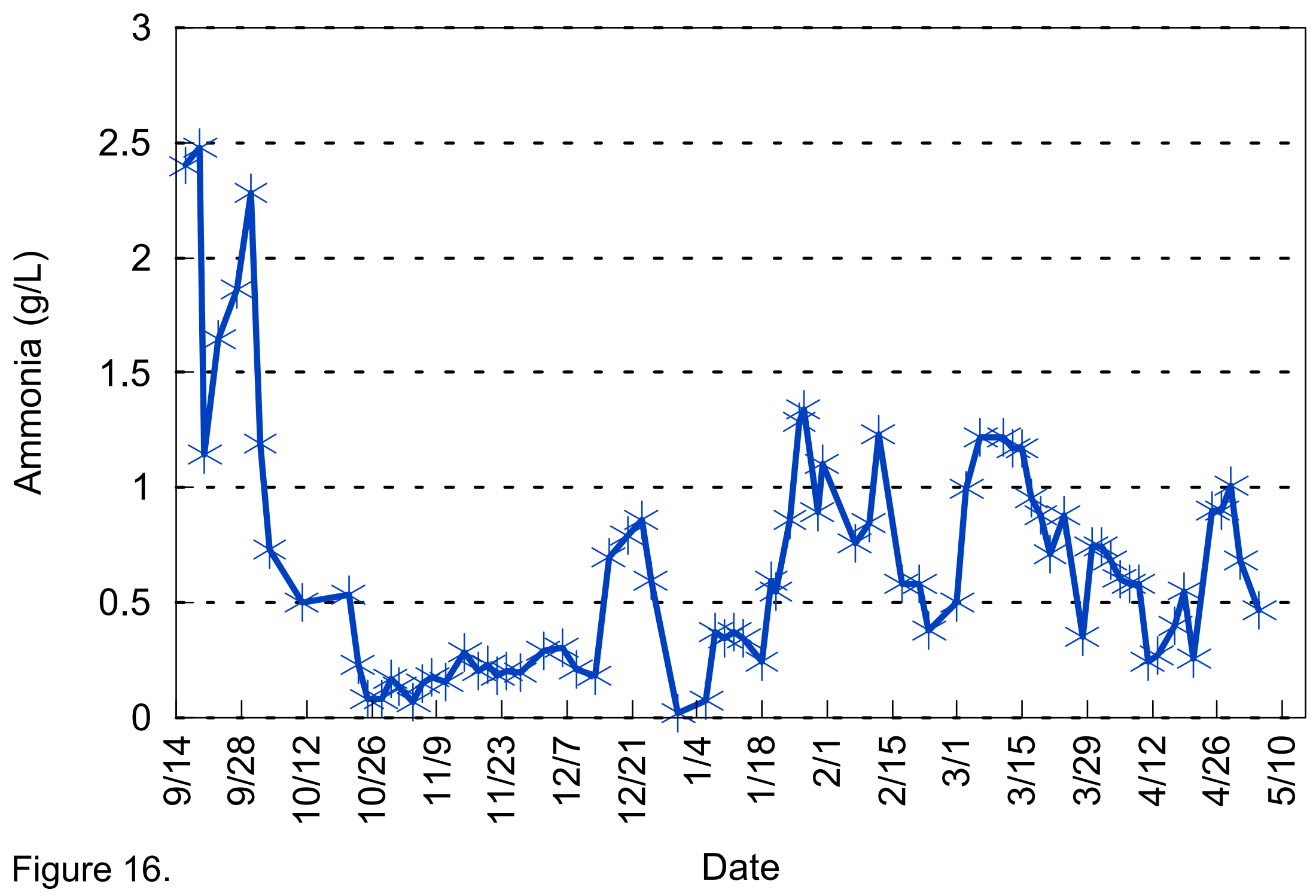




\section{Pilot Scale HSAD Organic Loading Operating Phase}

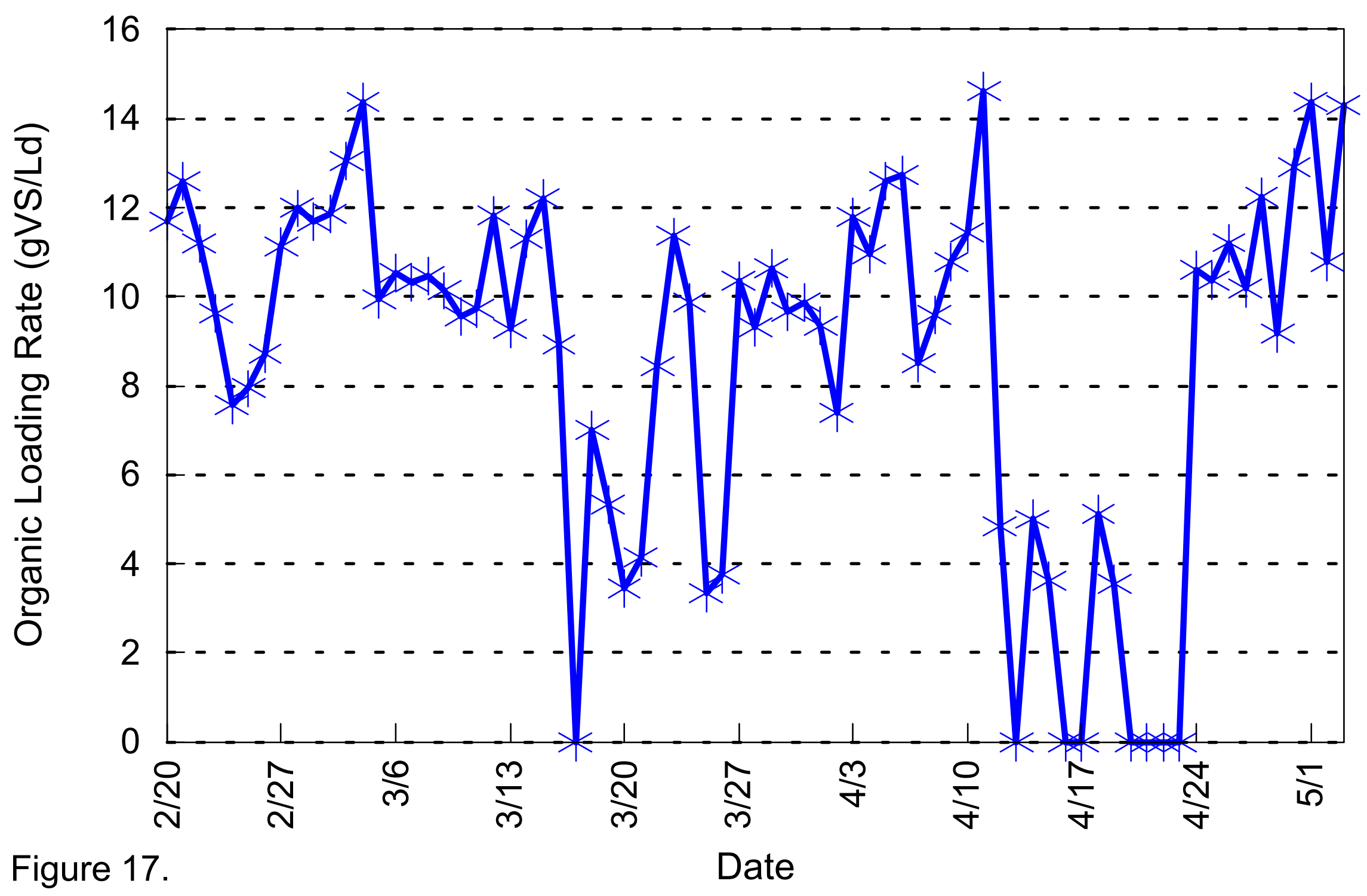




\section{Effects of Feedstock Total Solids and Dilution on Solids Retention Time}

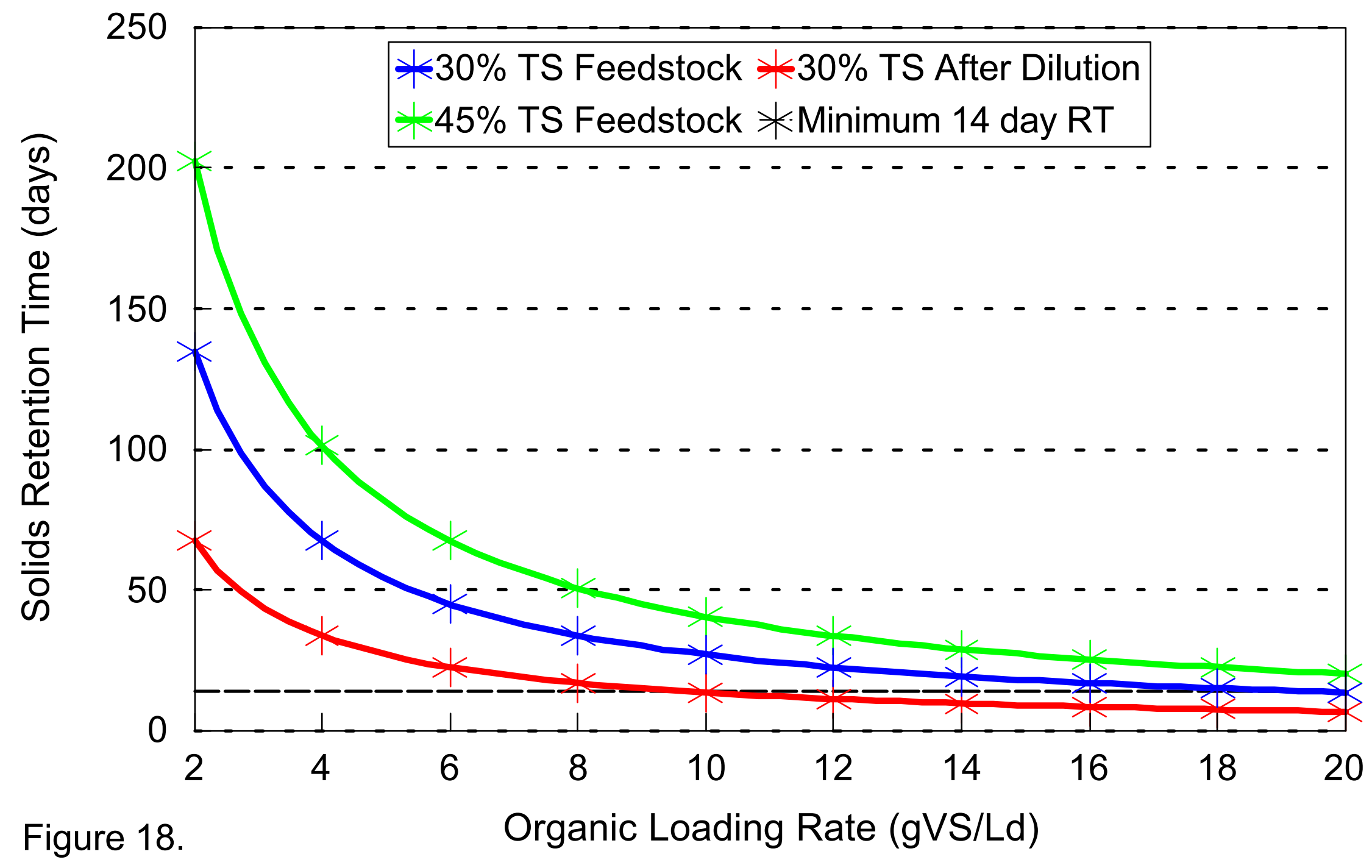




\section{References}

\section{SCIENTIFIC PUBLICATIONS}

1. Rivard, C.J., Duff, B.D., Dickow, J.H., Wiles, C.C., Nagle, N.J., Gaddy, J.L., and E.C. Clausen 1998 "Demonstration-Scale Evaluation of a Novel High Solids Anaerobic Bioconversion Process for Converting Organic Wastes to Fuel Gas and Compost," Appl. Biochem. Biotech.70-72: 687695.

2. Rivard, C.J., Kay, B.D., Kerbaugh, D.H., Nagle, N.J., and M.E. Himmel 1995 "Horsepower Requirements for High-Solids Anaerobic Digestion," Appl. Biochem. Biotech. 51/52: 155-162.

3. Rivard, C.J., Rodriguez, J.B., Nagle, N.J., Self, J.R., Kay, B.D., Soltanpour, P.N., and R.A. Nieves 1995 "Anaerobic Digestion of Municipal Solid Waste: Utility of Process Residues as a Soil Amendment," Appl. Biochem. Biotech. 51/52: 125-135.

4. $\quad$ Rivard, C.J., Nagle, N.J., Nieves, R.A., Shahbazi, A., and M.E. Himmel 1994. "Anaerobic Digestion of Municipal Solid Waste: Enhanced Cellulolytic Capacity Through High-Solids Operation Compared to Conventional Low-Solids Systems," ACS Books, American Chemical Society, Washington, DC, pp 438-451.

5. Rivard, C.J., Nieves, R.A., Nagle, N.J., and M.E. Himmel 1994. "Evaluation of Discrete Cellulase Enzyme Activities from Anaerobic Digester Sludge Fed a Municipal Solid Waste Feedstock," Appl. Biochem. Biotech. 45/46:453-462.

6. Rivard, C.J. 1994. "Advancements in Anaerobic Bioconversion of Solid Organic Wastes," in Proceedings of the 1994 Food Industry Environmental Conference, Georgia Tech Research Institute, Atlanta, GA, pp 119-124.

7. Overend, R.P., and C.J. Rivard 1993. "Thermal and Biological Gasification," in Proceedings of the First Conference of the Americas: Energy, Environment, Agriculture, and Industry.

8. Rivard, C.J., and N.J. Nagle 1993. "Enhanced Disposal of Sewage-Derived Fat, Oil, and Grease Employing Thermophilic Anaerobic Biodegradation," in Proceedings of the 1993 Food Industry Environmental Conference.

9. Rivard, C.J. 1993. "Anaerobic Bioconversion of Municipal Solid Wastes Using a Novel High Solids Design: Maximum Organic Loading Rate and Comparison with Low Solids Reactor Systems," Appl. Biochem. Biotech. 39/40:107-117.

10. Rivard, C.J., N.J. Nagle, W.S. Adney, and M.E. Himmel 1993. "Anaerobic Bioconversion of Municipal Solid Wastes: Effects of Total Solids Levels on Microbial Numbers and Hydrolytic Enzyme Activities," Appl. Biochem. Biotech. 39/40:71-82. 
11. Rivard, C.J. 1992. "Comparison of High Solids Anaerobic Fermentation of Selected Biomass Feedstocks with Processed Municipal Solid Waste (RDF-MSW) for the Production of Methane," in Proceedings of Energy from Biomass and Wastes XVI.

12. Rivard, C.J., and N.J. Nagle 1992. "Anaerobic Bioconversion of Tuna Processing Wastes with MSW," in Proceedings of the Second United States Conference on Municipal Solid Waste Management.

13. Rivard, C.J., and N.J. Nagle 1992. "Biological Disposal of Tuna Processing Wastes Using a Novel Anaerobic Composting System," in Proceedings of the 1992 Food Industry Environmental Conference, 119-127.

14. Adney, W.S., C.J. Rivard, M. Shiang, and M.E. Himmel 1991. "Anaerobic Digestion of Lignocellulosic Biomass and Wastes: Cellulases and Related Enzymes" Appl. Biochem. Biotech. 30: $165-183$.

15. Rivard, C.J., W.S. Adney, and M.E. Himmel 1991. "Enzymes in Anaerobic Municipal Solid Waste Disposal," in Enzymes in Biomass Conversion, G. Leatham and M. Himmel, eds., ACS Books, Washington, DC, pp. 22-35.

16. Rivard, C.J. 1991. "Biodegradation of Plastics." J. Environ. Health 53: 24-26.

17. Rivard, C.J., T.B. Vinzant, M.E. Himmel, and K. Grohmann 1990. "Anaerobic Biodegradation of Starch and Cellulose Acetate Plastic Copolymers." in Proceedings from the Corn Utilization Conference III, Section V, pp. 1-4, National Corn Growers Association, St. Louis, MO.

18. Rivard, C.J., T.B. Vinzant, W.S. Adney, K. Grohmann, and M.E. Himmel 1990. "Anaerobic Digestibility of Two Processed Municipal Solid Waste Materials," Biomass 23: 201-214.

19. Vinzant, T.B., W.S. Adney, K. Grohmann, and C.J. Rivard, 1990. "Aerobic and Anaerobic Digestion of Processed Municipal Solid Waste: Effects of Retention Time on Cellulose Degradation". Appl. Biochem. Biotech. 24/25: 765-771.

20. Rivard, C.J., M.E. Himmel, T.B. Vinzant, W.S. Adney, C.E. Wyman, and K. Grohmann, 1990. "Anaerobic Digestion of Processed Municipal Solid Waste Using a Novel High Solids Reactor: Maximum Solids Levels and Mixing Requirements." Biotech. Lett. 12: 235-240.

21. Rivard, C.J. 1989. "Municipal Solid Waste: The Mounting Problem". J. Environ. Health 52: 99100.

22. Rivard, C.J., T.B. Vinzant, W.S. Adney, and K. Grohmann, 1989. "Waste to Energy: Nutrient Requirements for Aerobic and Anaerobic Digestion". J. Environ. Health 52: 96-99.

23. Adney, W.S., C.J. Rivard, K. Grohmann, and M.E. Himmel, 1989. "Characterization of Polysaccharidase Activity Optima in the Anaerobic Digestion of Municipal Solid Waste," Biotech. Lett. 11: 207-210. 
24. Adney, W.S., C.J. Rivard, K. Grohmann, and M.E. Himmel, 1989. "Detection of Extracellular Hydrolytic Enzymes in the Anaerobic Digestion of Municipal Solid Waste," Biotech. and Appl. Biochem. 11: 387-400.

25. Rivard, C.J., M.E. Himmel, T.B. Vinzant, W.S. Adney, C.E. Wyman, and K. Grohmann, 1989. "Development of a Novel Laboratory Scale High Solids Reactor for Anaerobic Digestion of Municipal Solid Wastes for the Production of Methane". Appl. Biochem. and Biotech. 20/21: 461-478.

26. Rivard, C.J., F. Bordeaux, J.M. Henson, and P.H. Smith, 1987. "Effects of Addition of Soluble Oxidants on the Thermophilic Anaerobic Digestion of Biomass to Methane". Appl. Biochem. and Biotech. 17:245-262.

27. Henson, J.M., F.M. Bordeaux, C.J. Rivard, and P.H. Smith, 1986. "Quantitative Influences of Butyrate or Propionate on Thermophilic Production of Methane from Biomass". Appl. Environ. Microbiol. 51: 288-292.

\section{GOVERNMENT PUBLICATIONS}

28. Rivard, C. "Intermediate-Scale High Solids Anaerobic Digestion," A Progress Report to the Municipal Solid Waste Management Program, June 1994.

29. Rivard, C.J. "Anaerobic Digestion as a Waste Disposal Option for American Samoa," Progress Report: September 1992.

30. Rivard, C.J., T.B. Vinzant, W.S. Adney, and K. Grohmann. "Anaerobic High Solids Fermentation of Feedstocks from the Western Regional States for the Production of Methane," Final Report to the Western Area Power Administration, Biomass Program, January 1990.

31. Rivard, C.J., M.E. Himmel, and K. Grohmann. "Biodegradation of Plastics," in "Assessment of Biobased Materials," H.L. Chum ed., SERI/TR-234-3610, Dec. 1989.

32. Rivard, C.J., M.E. Himmel, T.B. Vinzant, W.S. Adney, C.E. Wyman, and K. Grohmann. "Anaerobic High Solids Fermentation of Processed Municipal Solid Wastes for the Production of Methane", SERI/SP-231-3520, Jan. 1989.

33. de Macario, E.C., A.J.L. Macario, C.J. Rivard, and K. Grohmann. "Use of Antibody Probes to Monitor Hydrolytic Microbes in Municipal Solid Waste Anaerobic Digesters", SERI/SP-2313520, Jan. 1989.

34. Himmel, M.E., W.S. Adney, C.J. Rivard, and K. Grohmann. "Detection of Extra-Cellular Hydrolytic Enzymes in Anaerobic Digestion of MSW", SERI/SP-231-3520, Jan. 1989.

35. Rivard, C.J., M.E. Himmel, T.B. Vinzant, W.S. Adney, C.E. Wyman, and K. Grohmann.

"Anaerobic High Solids Fermentation of Processed Municipal Solid Wastes for the Production of Methane", SERI/CP-232-0322, Dec. 1987. 
36. Himmel, M.E., W.S. Adney, C.J. Rivard, and K. Grohmann. "Detection of Extra-Cellular Hydrolytic Enzymes in Anaerobic Digestion of MSW", SERI/CP-232-0320, Dec. 1987.

37. de Macario, E.C., A. Macario, C.J. Rivard, and K. Grohmann. "Use of Monoclonal Antibody Probes to Track External Additions of Improved Hydrolytic Microorganisms in a Municipal Solid Waste Anaerobic Digester", SERI/CP-232-0323, Dec. 1987. 


\section{Acknowledgments}

Special thanks to Donald Walter and Simon Friedrich of the U.S. Department of Energy, Washington, DC, and John Shupe and Eliene Yoshinaka of the DOE Pacific Site Office, Honolulu, HI, for their belief in the technology and its application. Their long ter support, both technically and financially was instrumental to the HSAD process development.

Sincere thanks to the National Renewable Energy Laboratory and especially, Helena Chum, Bi Gupta, Carlton Wiles, Phil Shepard and Lynda Wentworth who believed in the technology and fought for and administered funding for its development.

We thank early contributors to the fundamental research and development aspects of the technology which ultimately lead to the development of the pilot demonstration unit including, Charles Wyman, Karl Grohmann, Michael Himmel, William Adney, Todd Vinzant, Nick Nagle and Brian Kay.

Continuing thanks to our industrial participants, including Cliff Ronenberg (CR\&R), Mike Silva (Athens Disposal), Ian Boatwood (Chicken of the Sea International), and Chris Koebler (Heinz Pet Products) for their specific information, comments and waste materials.

Additional thanks go to James Schmitt of Lone Tree Consulting for helping out in the pinch toward the development of the process control system. 


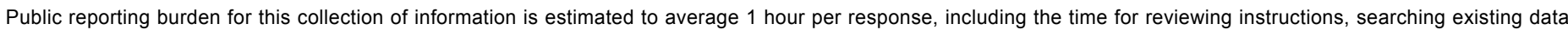

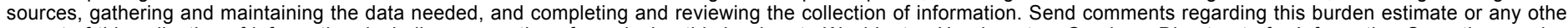

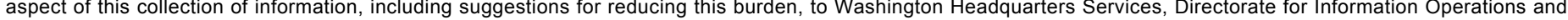

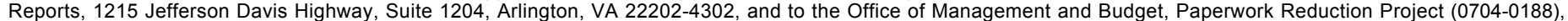
Washington, DC 20503.

\begin{tabular}{|l|l|l}
\hline 1. AGENCY USE ONLY (Leave blank) & $\begin{array}{c}\text { 2. REPORT DATE } \\
\text { April } 1999\end{array}$ & 3. REPORT TYPE AND DATES COVERED \\
& Subcontract Report \\
\hline
\end{tabular}

\section{TITLE AND SUBTITLE}

Recycling and Energy Recovery Pilot Project: Project Report and Future Efforts

5. FUNDING NUMBERS

IT635151

8. PERFORMING ORGANIZATION REPORT NUMBER

Pinnacle Biotechnologies International, Inc.

1667 Cole Boulevard, Suite 400

Golden, CO 80401-3393

\section{SPONSORING/MONITORING AGENCY NAME(S) AND ADDRESS(ES)}

National Renewable Energy Laboratory

1617 Cole Boulevard

Golden, CO 80401-3393

10. SPONSORING/MONITORING AGENCY REPORT NUMBER

NREL/SR-570-26158

\section{SUPPLEMENTARY NOTES}

12a. DISTRIBUTION/AVAILABILITY STATEMENT

National Technical Information Service

U.S. Department of Commerce

5285 Port Royal Road

Springfield, VA 22161 12b. DISTRIBUTION CODE

13. ABSTRACT (Maximum 200 words) A novel bioprocessing technology was developed that efficiently converts negative-value organic waste, including domestic refuse, animal manures, industrial wastes, food processing wastes, and municipal sewage sludge into saleable products, including fuel gas and compost. This technology is known as high solids anaerobic digestion and was developed at NREL from fundamental research to laboratory- and intermediatescale system evaluations.

\section{SUBJECT TERMS}

recycle, energy, high solids anaerobic digestion (HSAD), bioprocessing

17. SECURITY CLASSIFICATION OF REPORT
18. SECURITY CLASSIFICATION OF THIS PAGE
19. SECURITY CLASSIFICATION OF ABSTRACT
15. NUMBER OF PAGES

63

16. PRICE CODE

20. LIMITATION OF ABSTRACT 